\title{
The effect of temperature-dependent material properties on simple thermal models of subduction zones
}

\author{
Iris van Zelst $^{1}$, Cedric Thieulot ${ }^{2}$, Timothy J. Craig ${ }^{1}$ \\ ${ }^{1}$ Institute for Geophysics and Tectonics, School of Earth and Environment, University of Leeds, Leeds, \\ LS2 9JT, United Kingdom \\ ${ }^{2}$ Department of Earth Sciences, Utrecht University, Utrecht, The Netherlands
}

\begin{abstract}
$8 \quad$ Key Points:
- We study the effect of temperature-dependent thermal conductivity, heat capacity, and density on simple subduction models

- Using temperature-dependent thermal properties alters the modelled seismogenic zone size and location of dehydration reactions

- Thermo(-mechanical) models of subduction zones should ideally include temperaturedependent thermal parameters
\end{abstract}

This manuscript is a preprint which has been submitted for publication.

It has not undergone peer review yet.

Subsequent versions of this manuscript may have slightly different content.

If accepted, the final version of this manuscript will be available

via the 'Peer-reviewed Publication DOI' link on the right - hand side of this webpage. Please feel free to contact any of the authors; we welcome feedback!

Twitter: @iris_van_zelst

Corresponding author: Iris van Zelst, i.vanzelst@leeds.ac.uk / iris.v.zelst@gmail.com 


\begin{abstract}
To a large extent, the thermal structure of a subduction zone determines where seismicity occurs through the transition from brittle to ductile deformation and the depth of dehydration reactions. Thermal models of subduction zones can help understand this seismicity by accurate modelling of the thermal structure of the subduction zone. Here, we assess a common simplification in thermal models of subduction zones, i.e., constant values for the thermal parameters. We use temperature-dependent functions constrained by lab estimates for the thermal conductivity, heat capacity, and density, to systematically test their effect on the resulting thermal structure of the slab. To isolate this effect, we use the well-constrained and thoroughly studied model setup of the subduction community benchmark by van Keken et al. (2008) in a 2D finite element code. To ensure a self-consistent and realistic initial temperature-profile for the slab, we implement a 1D plate model for cooling of the oceanic lithosphere with an age of $50 \mathrm{Myr}$ in favour of the previously used half-space model in van Keken et al. (2008). Our results show that using temperature-dependent thermal parameters in thermal models of subduction zones result in a cooler plate, which leads to a larger estimated seismogenic zone and a larger depth at which dehydration reactions responsible for intermediate-depth seismicity occur. We therefore recommend that thermo(-mechanical) models of subduction take temperaturedependent thermal parameters into account for accurate modelling of the thermal structure of subduction zones.
\end{abstract}

\title{
Plain Language Summary
}

In a subduction zone, one tectonic plates dives below another one, which is paired with various forms of seismicity. The maximum size of the earthquakes and the location of the earthquakes is largely determined by the thermal structure of the subducting plate. To increase our understanding of seismicity in subduction zones, many studies have modelled this thermal structure. However, one of the common simplifications in the models is the use of constant thermal parameters in the equations, while lab experiments have shown that these parameters vary with temperature. Here, we test out various formulations of temperature-dependent thermal parameters to assess the effect on the resulting thermal structure of the subduction zone. We find that the thermal structure of a subducting slab indeed changes when temperature-dependent thermal parameters are used. More specifically, the subducting plate becomes colder, which results in a different potential maximum earthquake magnitude and a changed location for seismicity at depth. We therefore recommend that modelling studies take the temperature-dependence of thermal parameters into account to accurately model the thermal structure to provide some insight into seismicity.

\section{Introduction}

The thermal structure of subduction zones plays a vital role in controlling many geological and petrological processes, including the dehydration of the subducting plate (Peacock, 2001; Hacker, Abers, \& Peacock, 2003), the subsequent hydration of the mantle and overriding plate (Peacock, 1993; G. Abers et al., 2017), and mineralogical variations, including serpentinisation (Hyndman \& Peacock, 2003). Furthermore, seismicity can often be related to both the thermal structure, and to various processes controlled by the pressure and temperature evolution of the slab (Scholz, 2019). For example, intermediatedepth earthquakes are associated with a process called dehydration embrittlement (e.g., Green \& Houston, 1995; Peacock, 2001; Hacker, Peacock, et al., 2003; Yamasaki \& Seno, 2003; Jung et al., 2004; Wang et al., 2017). Water is released during the compositional evolution of the slab, as hydrous minerals progressively transform to less hydrous phases (e.g., from blueschist to eclogite (van Keken et al., 2011)). The addition of free fluids to the system acts against the pressure of the surrounding rock, permitting earthquakes to 
occur at depths where the confining pressure is otherwise too great. These phase transitions are linked to specific temperature and pressure conditions, suggesting that a thorough grasp of those conditions at depth could indicate where intermediate-depth seismicity would be likely to occur (e.g., Hacker, Abers, \& Peacock, 2003). Similarly, megathrust earthquakes occur within the seismogenic zone, the downdip limit of which is thought to be the transition from brittle to ductile deformation (Peacock \& Hyndman, 1999; Scholz, 2019), and is again controlled, directly or indirectly, by temperature, with isotherms of 350-450 ${ }^{\circ} \mathrm{C}$ typically linked to this change (Hyndman \& Wang, 1993; Hyndman et al., 1997; Gutscher \& Peacock, 2003).

From these examples, it becomes clear that it is important to have a thorough understanding of the thermal structure of a slab in order to better understand subduction seismicity. However, it is hard to obtain direct observational data on the thermal structure of the slab, due to the inaccessibility of subduction zones and the difficulty of obtaining data at great depths (i.e., larger than $10 \mathrm{~km}$ ).

The dependence of seismic wavespeeds on temperature allows seismic tomography studies to give a broad overview of the large-scale thermal structure of the subduction zone as a whole, but such studies typically lack the resolution to infer the thermal structure of the slab itself in great detail (e.g., G. A. Abers et al., 2006; Pozgay et al., 2009). In addition, the observed velocity anomalies in tomographic models are not exclusively due to temperature, and wavespeed variations are also related to other factors, particularly composition, density, mineralogy, and the presence of fluids (e.g., Hacker, Abers, \& Peacock, 2003; Blom et al., 2017). Whilst bore-hole experiments and marine heat flow measurements can provide vital insights into the thermal state of the shallow seismogenic zone (e.g., Hyndman \& Wang, 1993; Chang et al., 2010; Fulton et al., 2013; R. Harris et al., 2013; Yabe et al., 2019), such measurements are extremely local and fail to give a good overview of the conditions of the subduction zone as a whole, especially the finer details of the temperature structure within the slab.

In light of the limited available data on the thermal structure of subduction zones, geodynamic numerical modelling provides a way of investigating the complete temperature field of subduction zones in relation to the thermal and dynamic evolution of the slab (see Peacock, 2020, for an overview). The starting point for many thermal models of subduction zones are one-dimensional models of the cooling of oceanic lithosphere that define the thermal structure of the slab for a certain plate age, including half-space cooling models and more advanced plate models (McKenzie \& Sclater, 1969; Parsons \& Sclater, 1977; Stein \& Stein, 1994; Hillier \& Watts, 2005; McKenzie et al., 2005; Crosby et al., 2006; Emmerson \& McKenzie, 2007; Richards et al., 2018). Extending this thermal modelling to two dimensions to study the thermal evolution of a subduction zone in steady state has provided insights into the predicted location of dehydration and melting processes linked to intermediate-depth seismicity (Ponko \& Peacock, 1995; Peacock \& Wang, 1999; van Keken et al., 2002; G. A. Abers et al., 2006; Syracuse et al., 2010; Van Keken et al., 2012; van Keken et al., 2019). Apart from pure thermal models, thermo-mechanical models with various complexities such as melting and dehydration reactions have also been employed (e.g., T. V. Gerya \& Meilick, 2011; T. V. Gerya, 2011; Faccenda et al., 2012; Arcay, 2017; Beall et al., 2021), leading to insights into subduction dynamics and estimates of the depth of intermediate-depth seismicity and the geometry of the megathrust. When these types of models additionally account for an inertia term in so-called seismo-thermo-mechanical models, megathrust slip events are resolved allowing for estimates of the maximum size of the seismogenic zone and the distribution of seismicity in a given subduction geometry (van Dinther, Gerya, Dalguer, Mai, et al., 2013; van Dinther, Gerya, Dalguer, Corbi, et al., 2013; van Dinther et al., 2014; Herrendörfer et al., 2015; Van Zelst et al., 2019; Petrini et al., 2020; Brizzi et al., 2020). These types of modelling have the advantage that the temperature can be calculated across the entire subduction zone with arbitrary resolution. However, the results of the model depend on its initial 
and boundary conditions and the assumptions that enter the model at various stages (van Zelst et al., 2021).

Numerical models of the temperature structure of subduction zones are subject to a range of simplifications. One, which we seek to address here, is that the thermal parameters in the model, i.e., the thermal conductivity, heat capacity, and density, are assumed to be constant or merely material-dependent. In contrast, laboratory experiments have shown that these parameters actually depend on temperature and can differ as much as a factor of 2 depending on the temperature (e.g., Berman, 1988; Berman \& Aranovich, 1996; Seipold, 1998; A. Hofmeister, 1999; Xu et al., 2004; Wen et al., 2015; Su et al., 2018). The inclusion of such parameters into models for the cooling of oceanic lithosphere has made a significant difference to both the resulting thermal structure, and its interpretation and implications (Denlinger, 1992; McKenzie et al., 2005; Richards et al., 2018). Initial one-dimensional studies have highlighted the potential for a similar impact on the more complex thermal structure of subduction zones (Emmerson \& McKenzie, 2007).

Given the sensitivity of the various processes mentioned above to small-scale variations in the temperature evolution of the slab, we therefore seek to quantify the impact that the incorporation of the temperature-dependence of thermal parameters may have on subduction zone thermal structure, and to build towards their routine incorporation.

In order to assess the effect of temperature-dependent thermal parameters on the resulting thermal structure of the slab, we perform a systematic study into this by using the well-constrained setup of the subduction community benchmark by van Keken et al. (2008) with the addition of temperature-dependent functions for the thermal conductivity, heat capacity and density as constrained by laboratory experiments (Section 2). We show that using temperature-dependent parameters in geodynamic models significantly changes the resultant thermal structure of the slab, relative to models with fixed values (Section 3). To relate this change in thermal structure to expected seismicity and mineralogical changes in the slab, we discuss the change in the expected depth of intermediatedepth seismicity when temperature-dependent thermal parameters are taken into account (Section 4). Going forwards, we recommend the inclusion of temperature-dependent thermal parameters in future thermal models of subduction zones, especially if inferences on seismicity are made.

\section{Methods}

We base our models on the subduction zone community benchmark presented by van Keken et al. (2008). We use the tailor-made two-dimensional finite element Python code $\mathrm{xFieldstone} \mathrm{(citation} \mathrm{of} \mathrm{git} \mathrm{repository} \mathrm{finalised} \mathrm{after} \mathrm{acceptance} \mathrm{of} \mathrm{the} \mathrm{manuscript)}$ to solve the incompressible Stokes equations with Crouzeix-Raviart elements and the conservation of energy using quadratic triangular elements. xFieldstone is based on Fieldstone_68 which is part of the open source Fieldstone collection of educational finite element codes in computational geodynamics (https://cedrict.github.io/). The exact version of xFieldstone used to produce the results presented in this work can be found in the Zenodo repository (citation of final zenodo repository finalised after acceptance of the manuscript).

In the following, we first discuss the governing equations (Section 2.1) and rheology (Section 2.2) of the physical model. We then present the model setup (Section 2.3), our formulation for the thermal structure of the oceanic plate at the trench on the leftside of the model (Section 2.4), and the different functions we consider for the temperaturedependence of the thermal parameters (Section 2.5). Based on these functions, we define the parameter space of this study (Section 2.6) and detail the model diagnostics used in this work (Section 2.7). 


\subsection{Governing equations}

Following van Keken et al. (2008), we solve the incompressible formulation of the conservation of mass and momentum (i.e., the Stokes equations) for velocity $\boldsymbol{v}$ and pressure $p$ :

$$
\begin{aligned}
\boldsymbol{\nabla} \cdot \boldsymbol{v} & =0, \\
\nabla \cdot \boldsymbol{\sigma}^{\prime}-\nabla p+\rho \boldsymbol{g} & =\mathbf{0},
\end{aligned}
$$

where $\boldsymbol{\sigma}^{\prime}$ is the deviatoric stress tensor, $\rho$ is density, and $\boldsymbol{g}$ is the gravitational acceleration, which we assume to be $\mathbf{0}$ for the purposes of this study. We also solve for temperature $T$ using the steady-state conservation of energy without external heat sources:

$$
\rho C_{p}(\boldsymbol{v} \cdot \nabla T)-\nabla \cdot(k \nabla T)=0
$$

where $C_{p}$ is the heat capacity, and $k$ is the thermal conductivity. Unlike van Keken et al. (2008), we make these thermal parameters temperature-dependent instead of constants, as described in Section 2.5.

\subsection{Rheology}

We consider a purely viscous rheology and hence neglect any elastic and plastic contributions to the deformation. We relate stress to deformation through the deviatoric stress tensor $\sigma^{\prime}$ :

$$
\boldsymbol{\sigma}^{\prime}=2 \eta \dot{\varepsilon}
$$

where $\eta$ is the shear viscosity, and $\dot{\varepsilon}$ is the strain-rate tensor defined by

$$
\dot{\varepsilon}=\frac{1}{2}\left(\nabla \boldsymbol{v}+\nabla \boldsymbol{v}^{T}\right)
$$

Initially, we run sets of models with different viscous rheologies to successfully reproduce the different benchmark cases presented in van Keken et al. (2008) (Section S1; Figures S1S7). In the following, we confine ourselves to a rheology that combines the diffusion and dislocation creep mechanisms used in van Keken et al. (2008). We implement this temperaturedependent rheology through an effective shear viscosity $\eta_{\text {eff }}$.

For the diffusion creep rheology, we use the simplified diffusion creep viscosity formulation $\eta_{\text {diff }}$ for olivine, where we assume zero activation volume and ignore any effect caused by hydration and grain-size dependence:

$$
\eta_{\text {diff }}=A_{\text {diff }} \exp \left(\frac{E_{\text {diff }}}{R T}\right)
$$

where $A_{\text {diff }}$ is a prefactor, $E_{\text {diff }}$ is the activation energy, and $R$ is the universal gas constant. Similarly, we use the following expression for a dislocation creep rheology:

$$
\eta_{\text {disl }}=A_{\text {disl }} \exp \left(\frac{E_{\text {disl }}}{n R T}\right) \dot{\varepsilon}_{I I}^{(1-n) / n}
$$


where $A_{\text {disl }}$ is a prefactor, $n$ is the power-law exponent and $\dot{\varepsilon}_{I I}=\sqrt{\dot{\varepsilon}_{x x}^{2}+\dot{\varepsilon}_{x y}^{2}}$ is the square root of the second invariant of the deviatoric strain rate tensor (i.e., effective deviatoric strain rate).

We combine these formulations for diffusion and dislocation creep into one rheology by assuming two viscous dampers in series (Schmeling et al., 2008):

$$
\eta_{\text {comb }}=\frac{\eta_{\text {diff }} \cdot \eta_{\text {disl }}}{\eta_{\text {diff }}+\eta_{\text {disl }}}=\left(\frac{1}{\eta_{\text {diff }}}+\frac{1}{\eta_{\text {disl }}}\right)^{-1}
$$

To avoid unrealistically high stresses, we limit the maximum viscosity in the model to $\eta_{\max }=10^{26} \mathrm{~Pa}$ s for both the diffusion and dislocation creep rheology, such that the effective viscosity $\eta_{\text {eff }}$ becomes

$$
\eta_{\mathrm{eff}}=\left(\frac{1}{\eta_{\mathrm{comb}}}+\frac{1}{\eta_{\max }}\right)^{-1}
$$

\subsection{Model setup}

We use the two-dimensional model setup of the community benchmark for subduction zone modelling presented by van Keken et al. (2008) (Figure 1). We consider a domain that is $L_{x}=660 \mathrm{~km}$ wide and $L_{y}=600 \mathrm{~km}$ deep with the origin of the coordinate system at the lower left corner and the $y$-axis positive upwards. We discretise the domain by means of a structured triangular grid with a uniform resolution of $2.5 \mathrm{~km}$, resulting in $528 \times 480$ triangular elements. We define a simple slab geometry with a $45^{\circ}$ dip angle originating at the top left corner and a $50 \mathrm{~km}$ thick overriding plate at the top of the model. The remaining part of the model is the mantle wedge. Our chosen resolution ensures that the computational grid aligns with the bottom of the overriding plate and the wedge corner.

We fix the overriding plate by prescribing no slip (i.e., zero velocity in both the $x$ and $y$-direction) at its bottom boundary with the mantle wedge. We define the plate kinematics such that the downgoing slab subducts with a constant velocity of $5 \mathrm{~cm} /$ year by prescribing this velocity at the top of the slab from the corner point at $x=50 \mathrm{~km}$ and $y=550 \mathrm{~km}$ to the bottom of the domain. At the corner point itself, we prescribe zero velocity.

For the conservation of energy, we apply a constant $0^{\circ} \mathrm{C}$ temperature boundary condition along the top of the model domain. At the right-hand boundary, we apply a linear temperature gradient in the overriding plate from $T=0^{\circ} \mathrm{C}$ at the top to $1300^{\circ} \mathrm{C}$ at the bottom of the overriding plate at $y=550 \mathrm{~km}$. Below that, incoming material (i.e., $v_{x}<0$ ) is assigned the maximum temperature in the model $T_{\max }=1300^{\circ} \mathrm{C}$. At the left boundary, we apply either a half-space cooling model with a slab age $t_{s}$ of $50 \mathrm{Myr}$ and constant thermal parameters (as used in the benchmark of van Keken et al. (2008)), or a temperature profile extracted at $50 \mathrm{Myr}$ from a one-dimensional cooling plate model (following Richards et al. (2018), and discussed further in Section 2.4). The initial temperature field is constant with $T=0^{\circ} \mathrm{C}$.

We first solve the Stokes equations across the entire domain. As we are only interested in the velocity field in the mantle wedge, we overwrite the resulting velocity solution in the slab and overriding plate by our boundary conditions, i.e., no slip in the overriding plate and a constant subduction velocity of $5 \mathrm{~cm} /$ year in the slip. With the velocity solution determined, the heat equation is solved next. We then iteratively solve the Stokes and heat equation until convergence is reached, i.e. when the horizontal and vertical components of the velocity and the temperature compared to the previous iteration change less than a given tolerance. We choose a relative tolerance of $10^{-5}$ in our 

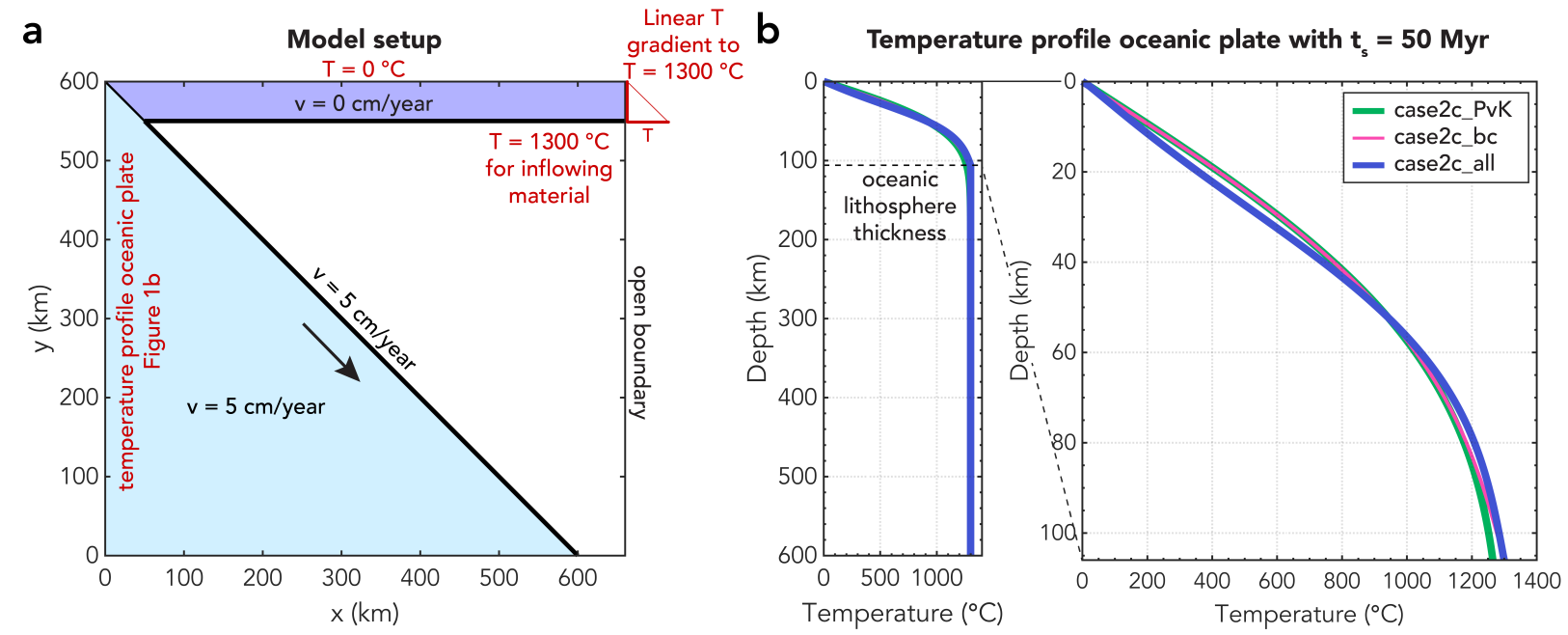

Figure 1. Model setup. (a) Model domain with kinematically prescribed overriding and subducting plate and temperature boundary conditions in red. Black bold lines indicate where we prescribe the velocities at the boundaries of the mantle wedge. (b) Different temperature boundary conditions for an oceanic plate with an age of 50 Myr used at the left-hand side of the model in (a) with a zoom of the top $106 \mathrm{~km}$ (i.e., the oceanic lithosphere thickness), below which the temperature is constant at $T=1300^{\circ} \mathrm{C}$. The half-space model used by van Keken et al. (2008) is indicated in a thick green line (model case2c_PvK). We also show the two end-member plate models of our parameter study with the plate model with constant thermal parameters in pink (model case2c_bc) and the plate model considering temperature-dependence for all thermal parameters (model case2c_all) indicted in blue. See the supplementary material (Figure S18) for the temperature profiles of all other models.

model runs for both velocity and temperature, although we also impose a maximum number of 50 iterations to limit the wall-time of the model. Tests show that employing a lower tolerance of $10^{-3}$ (reached before 50 iterations) changes the model diagnostics from Section 2.7 by less than $1{ }^{\circ} \mathrm{C}$ and has no effect on the reported isotherm depths. To prevent numerical oscillations in the solution that inhibit convergence of the temperature field, we limit the change of each new iteration solution via a relaxation parameter $r$ after the first iteration according to

$$
\phi_{\text {new }}=r \cdot \phi_{\text {new }}+(1-r) \cdot \phi_{\text {old }}
$$

where $\phi$ is the solution for $v_{x}, v_{y}$, and $T$. This relaxation step is applied to the velocity components after the Stokes solve and to the temperature after the heat equation solve. After trial and error, we choose $r=0.8$, which results in robust convergence across our model runs.

\subsection{Thermal structure of the oceanic plate at the trench}

As the left-hand boundary condition for the conservation of energy, we prescribe the thermal structure of the incoming oceanic plate. In the original community benchmark, van Keken et al. (2008) used a simple half-space cooling model (Turcotte \& Schubert, 2002) with a plate age of $50 \mathrm{Myr}$ with constant values for the thermal conductivity, heat capacity, and density: 


$$
T(y)=T_{\max } \cdot \operatorname{erf}\left(\frac{L_{y}-y}{2 \sqrt{\frac{k}{\rho C_{p}} t_{s}}}\right) .
$$

However, the half-space cooling model does not satisfy petrological constraints and fails to satisfy data for plate ages greater than $\sim 80 \mathrm{Ma}$ (Richards et al., 2018). Hence, we follow Richards et al. (2018) by including a more complex and realistic plate model as input for the temperature profile of the incoming oceanic plate. This plate model also has the advantage that it easily incorporates temperature-dependent thermal parameters, which results in consistency between the thermal structure of the incoming plate and the thermal structure we solve for in the rest of the domain.

We calculate the structure of the incoming oceanic plate in a linked, separate Python script, with the coordinate convention that the $y$-axis is positive downwards. The thermal structure of the oceanic plate is based on the one-dimensional heat equation

$$
\frac{\partial\left(\rho C_{p} T\right)}{\partial t}=\frac{\partial}{\partial y}\left(k \frac{\partial T}{\partial y}\right)
$$

Following McKenzie et al. (2005) and Richards et al. (2018), we discretise this equation using a one-dimensional time- and space-centered Crank-Nicolson finite difference scheme that is stable in both space and time and solve it numerically with a predictor-corrector step (Press et al., 1992) according to:

$$
\begin{aligned}
-A \frac{k_{j-\frac{1}{2}}^{m}}{\Delta y_{j-1}^{m}} \cdot T_{j-1}^{n+1}+\left[1+A\left(\frac{k_{j+\frac{1}{2}}^{m}}{\Delta y_{j}^{m}}+\frac{k_{j-\frac{1}{2}}^{m}}{\Delta y_{j-1}^{m}}\right)\right] \cdot T_{j}^{n+1}-A \frac{k_{j+\frac{1}{2}}^{m}}{\Delta y_{j}^{m}} \cdot T_{j+1}^{n+1}= \\
A \frac{k_{j-\frac{1}{2}}^{m}}{\Delta y_{j-1}^{m}} \cdot T_{j-1}^{n}+\left[1-A\left(\frac{k_{j+\frac{1}{2}}^{m}}{\Delta y_{j}^{m}}+\frac{k_{j-\frac{1}{2}}^{m}}{\Delta y_{j-1}^{m}}\right)\right] \cdot T_{j}^{n}+A \frac{k_{j+\frac{1}{2}}^{m}}{\Delta y_{j}^{m}} \cdot T_{j+1}^{n}+B,
\end{aligned}
$$

with

$$
A=\frac{\Delta t}{\rho_{j}^{m} C_{p, j}^{m}\left(\Delta y_{j}^{m}+\Delta y_{j-1}^{m}\right)},
$$

where $m=n$ for the predictor step and $m=n+\frac{1}{2}$ for the corrector step. Additionally, we have

$$
B=-\frac{T_{j}^{n}\left(\rho_{j}^{n} C_{p, j}^{n}-\rho_{j}^{n-1} C_{p, j}^{n-1}\right)}{\rho_{j}^{n} C_{p, j}^{n}}
$$

for the predictor step, and

$$
B=-\frac{\left(T_{j}^{n+1}+T_{j}^{n}\right)\left(\rho_{j}^{n+1} C_{p, j}^{n+1}-\rho_{j}^{n} C_{p, j}^{n}\right)}{\rho_{j}^{n+1} C_{p, j}^{n+1}+\rho_{j}^{n} C_{p, j}^{n}}
$$

for the corrector step.

As input parameters, we choose a constant $\Delta z$ of $1000 \mathrm{~m}$ and a constant time step $\Delta t=1000$ year. We have the same temperature boundary conditions as the $2 \mathrm{D}$ model 
domain for consistency, with a surface temperature of $0^{\circ} \mathrm{C}$ and a maximum temperature (mantle potential temperature) of $1300^{\circ} \mathrm{C}$. We choose a plate thickness of $106 \mathrm{~km}$ in accordance with the optimum plate thickness found by Parsons and Sclater (1977); Sclater et al. (1980); McKenzie et al. (2005) based on heat flow observations. We recognise that this plate thickness diverges from the results of Richards et al. (2018), but their result involved the inclusions of compositional variability, in addition to the thermal dependence of material properties, which we do not include here. Hence, we use the older plate thickness value determination of McKenzie et al. (2005).

We solve for the temperature evolution of the incoming oceanic plate with the desired thermal parameters (Section 2.5) for $200 \mathrm{Myr}$, which we store in a lookup table (Figures S8-S17). The main part of the code then extracts the relevant temperature profile for a plate age of $50 \mathrm{Myr}$ (van Keken et al., 2008) as input for the left boundary of the model domain, taking into account the different coordinate system conventions and the cubic interpolation between the 1D finite difference coordinates and finite element nodes in case of differing resolutions. We then solve the entire system using tridiagonal elimination.

\subsection{Temperature-dependent thermal parameters}

We use temperature-dependent expressions for the thermal conductivity, heat capacity, and density, using parameterisations based on observational experimental data for the way in which these values change with changing temperature.

Following McKenzie et al. (2005), we approximate the analytical expression for temperaturedependent thermal conductivity (Figure 2a) by A. Hofmeister (1999) with

$$
k_{H}(T)=\frac{b}{1+c T}+\sum_{m=0}^{3} d_{m}(T+273)^{m}
$$

where $k$ has units of $\mathrm{W} \mathrm{m}^{-1} \mathrm{~K}^{-1}$, although $T$ is in ${ }^{\circ} \mathrm{C}$ in this expression and $b=5.3$, $c=0.0015, d_{0}=1.753 \cdot 10^{-} 2, d_{1}=-1.0365 \cdot 10^{-4}, d_{2}=2.2451 \cdot 10^{-7}$, and $d_{3}=3.4071$. $10^{-11}$ are constants. This expression considers both heat transport and the radiative heat transfer by phonons.

Like McKenzie et al. (2005), we also implement the temperature-dependent conductivity for olivine proposed by $\mathrm{Xu}$ et al. (2004) to account for the large uncertainties in the temperature-dependence of the thermal conductivity:

$$
k_{X}(T)=k_{298}\left(\frac{298}{T+273}\right)^{n}
$$

where $T$ is in ${ }^{\circ} \mathrm{C}, k_{298}=4.08 \mathrm{~W} \mathrm{~m}^{-1} \mathrm{~K}^{-1}$ and $n=0.406$.

For the heat capacity (Figure 2b) $C_{p}$, we follow Berman (1988) to calculate the heat capacity of both fayalite and forsterite (McKenzie et al., 2005) such that we have

$$
C_{p, \mathrm{fa} \mid \mathrm{fo}}=\left(a_{0, \mathrm{fa} \mid \mathrm{fo}}+a_{1, \mathrm{fa} \mid \mathrm{fo}} \cdot T^{-\frac{1}{2}}+a_{3, \mathrm{fa} \mid \mathrm{fo}} \cdot T^{3}\right) \cdot \frac{1000}{m_{\mathrm{fa} \mid \mathrm{fo}}},
$$

where $C_{p}$ is the heat capacity in $\mathrm{J} \mathrm{kg}^{-1} \mathrm{~K}^{-1}$ and $T$ is in $\mathrm{K}$. We use updated values for the constants according to Berman and Aranovich (1996), resulting in $a_{0, \mathrm{fa}}=252, a_{1, \mathrm{fa}}=$ $-20.137 \cdot 10^{2}$, and $a_{3, \mathrm{fa}}=-6.219 \cdot 10^{7}$ for fayalite and $a_{0, \mathrm{fo}}=233.18, a_{1, \mathrm{fo}}=-18.016$. $10^{2}$, and $a_{3, \text { fo }}=-26.794 \cdot 10^{7}$ for forsterite. To obtain the heat capacity in the correct unit of $\mathrm{J} \mathrm{kg}^{-1} \mathrm{~K}^{-1}$, we multiply the equation from Berman (1988) where $C_{p}$ is in 


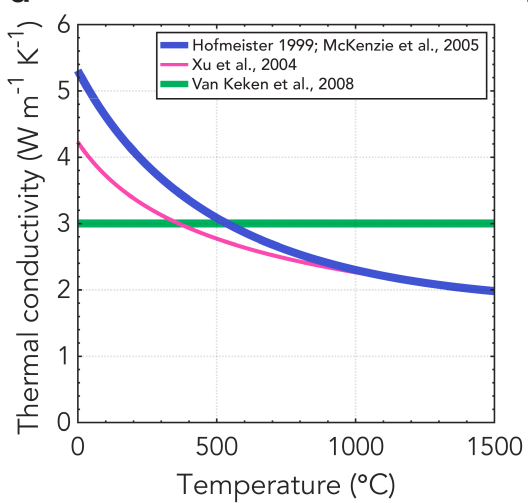

b

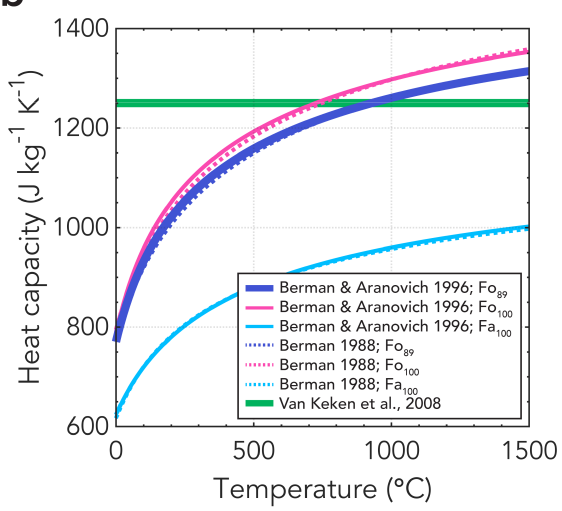

C

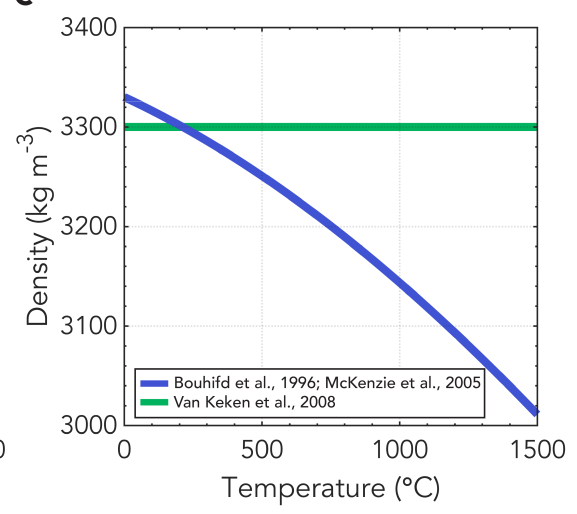

Figure 2. Temperature-dependence of (a) the thermal conductivity $k$ according to Xu et al. (2004) and the approximation of A. Hofmeister (1999) according to McKenzie et al. (2005); (b) the heat capacity $C_{p}$ according to Berman and Aranovich (1996) (solid lines) and Berman (1988) (dotted lines) for different ratios of forsterite (fo) and fayalite (fa); (c) the density according to the parameterisation by McKenzie et al. (2005) of Bouhifd et al. (1996). Constant values taken from van Keken et al. (2008) are plotted as reference in thick green lines.

$\mathrm{J} \mathrm{mol}{ }^{-1} \mathrm{~K}^{-1}$ with $\frac{1000}{m_{\text {fal fo }}}$, where $m_{\mathrm{fa} \mid \mathrm{fo}}$ is the molecular mass of fayalite (fa) or forsterite (fo). We then obtain the effective heat capacity in the model by assuming a molar fraction $f=0.11$ of fayalite in the mantle according to McKenzie et al. (2005):

$$
C_{p, \mathrm{eff}}=(1-f) \cdot C_{p, \mathrm{fo}}+f \cdot C_{p, \mathrm{fa}} .
$$

For the dependency of density on temperature (Figure 2c), we follow the parameterisation of McKenzie et al. (2005) based on the integration of the parameterisation of the temperature-dependence of the thermal expansivity according to Bouhifd et al. (1996):

$$
\rho=\rho_{0} \exp \left(-\left[\alpha_{0}\left(T-T_{0}\right)+\frac{\alpha_{1}}{2}\left(T^{2}-T_{0}^{2}\right)\right]\right),
$$

where $T$ is in $\mathrm{K}, \rho_{0}=3330 \mathrm{~kg} \mathrm{~m}^{-3}, T_{0}=273.15 \mathrm{~K}, \alpha_{0}=2.832 \cdot 10^{-5}$, and $\alpha_{1}=3.79$. $10^{-8}$.

Other formulations for the temperature-dependence of the thermal conductivity, heat capacity, and density than the ones described here are also available (e.g., Berman \& Brown, 1985; Seipold, 1998; Wen et al., 2015; Su et al., 2018), but here we limit ourselves to the formulations described in this section to test the first-order effect of such variability.

In our preferred formulations for the temperature-dependence of the thermal parameters, the thermal conductivity (A. Hofmeister, 1999; McKenzie et al., 2005) varies with a factor of 2.5 for the temperature range in our subduction zone models (i.e., 0 $1300^{\circ} \mathrm{C}$ ) with $k=5.3 \mathrm{~W} \mathrm{~m}^{-1} \mathrm{~K}^{-1}$ for $T=0^{\circ} \mathrm{C}$ and $k=2.1 \mathrm{~W} \mathrm{~m}^{-1} \mathrm{~K}^{-1}$ for $T=$ $1300^{\circ} \mathrm{C}$ (Figure 2). Similarly, the heat capacity ( $89 \%$ forsterite Berman \& Aranovich, 1996) varies by a factor of 1.65 over the temperature range $0-1300^{\circ} \mathrm{C}$. The temperaturedependence of the density (Bouhifd et al., 1996) is less pronounced, with a variation of approximately $9 \%$ in density for temperatures common to subduction zones. 


\subsection{Parameter space}

To systematically test the effect of temperature-dependent parameters on the thermal structure of subduction zones, we run the suite of simulations outlined in Table 1. We start with a reference model case2c_PvK based on the van Keken et al. (2008) benchmark models. Note that this model is not in the original suite of benchmark models of van Keken et al. (2008); the difference being that the rheology employed is a combination of diffusion and dislocation creep. Then, we first test the effect of adding the more complex temperature-profile of the plate model instead of the half-space cooling model in case2c_bc. We test the effect of the two different functions for the thermal conductivity with models case $2 \mathrm{c} \_\mathrm{k} 1$ and case $2 \mathrm{c} \_\mathrm{k} 2$, where the approximation of the function by A. Hofmeister (1999) is our preferred function, following McKenzie et al. (2005). Our preferred model for the heat capacity is the one where we use the function of Berman (1988) with updated values of Berman (1988) for a composition of $89 \%$ of forsterite and $11 \%$ fayalite (case2c_Cp6). We also test the effect of using the older values of Berman (1988) (case2c_Cp3), and a composition of $100 \%$ forsterite (case2c_Cp4) and 100\% fayalite (case2c_Cp5). Here, the numbers behind $k$ and $C_{p}$ in the model names refer to the flags used in the code to select different options for the temperature-dependent thermal parameters. We test the temperature-dependent density in case2c_rho. Finally, we combine our preferred functions of the thermal parameters in simulation case 2 c_all.

To illustrate how the different simulations differ in terms of temperature-dependence of the thermal parameters, we show the thermal diffusivity $\kappa$ in Figure 3 calculated according to

$$
\kappa=\frac{k}{\rho C_{p}} .
$$

Hence, when all thermal parameters $k, C_{p}$, and $\rho$ are temperature-dependent in the model case2c_all the overall temperature-dependency of the model is greatest. Compared to the constant thermal diffusivity used in the benchmark by van Keken et al. (2008) values are up to $319 \%$ larger and up to $28 \%$ smaller for the temperature range of our model. Large values for the diffusivity translate to cold regions heating up faster and hot regions cooling down slower. In general, Figure 3 shows that the thermal diffusivity is higher for low temperatures, meaning that the cold top of the slab will be heated faster. Similarly, the top of the overriding plate is cold, so a large thermal diffusivity will delay the onset of significant heat transfer from the overriding plate to the slab. Note that we do not use the thermal diffusivity within the code as the equations do not allow for this due to the temperature-dependence of the thermal parameters.

To illustrate the applicability of our results to the variety of subduction zones observed on Earth, we also run two end-member models with constant and temperaturedependent thermal parameters for a model with a younger $\left(t_{s}=20 \mathrm{Ma}\right)$ and older $\left(t_{s}=\right.$ $80 \mathrm{Ma}$ ) slab age, compared to our reference slab age of $t_{s}=50 \mathrm{Ma}$.

\subsection{Model diagnostics}

To assess our models and quantify their differences, we use the three diagnostics defined in the community benchmark by van Keken et al. (2008), as well as the maximum depth of certain isotherms. Following van Keken et al. (2008), we define a uniform rectangular grid of $111 \times 110$ points with $6 \mathrm{~km}$ spacing starting in the top left corner and stored row-wise. On this grid, we interpolate the discrete temperature field $T_{i j}$ in ${ }^{\circ} \mathrm{C}$ in a postprocessing step. Using this grid, we output (1) the temperature $T_{x=60 \mathrm{~km}}$ at the top of the slab at $y=540 \mathrm{~km}$ and $x=60 \mathrm{~km}$, just downdip of the mantle wedge corner; (2) the L2 norm of the temperature along the top of the slab $T_{\text {slab }}$ between $y=$ $600 \mathrm{~km}$ and $y=390 \mathrm{~km}$ as defined by 


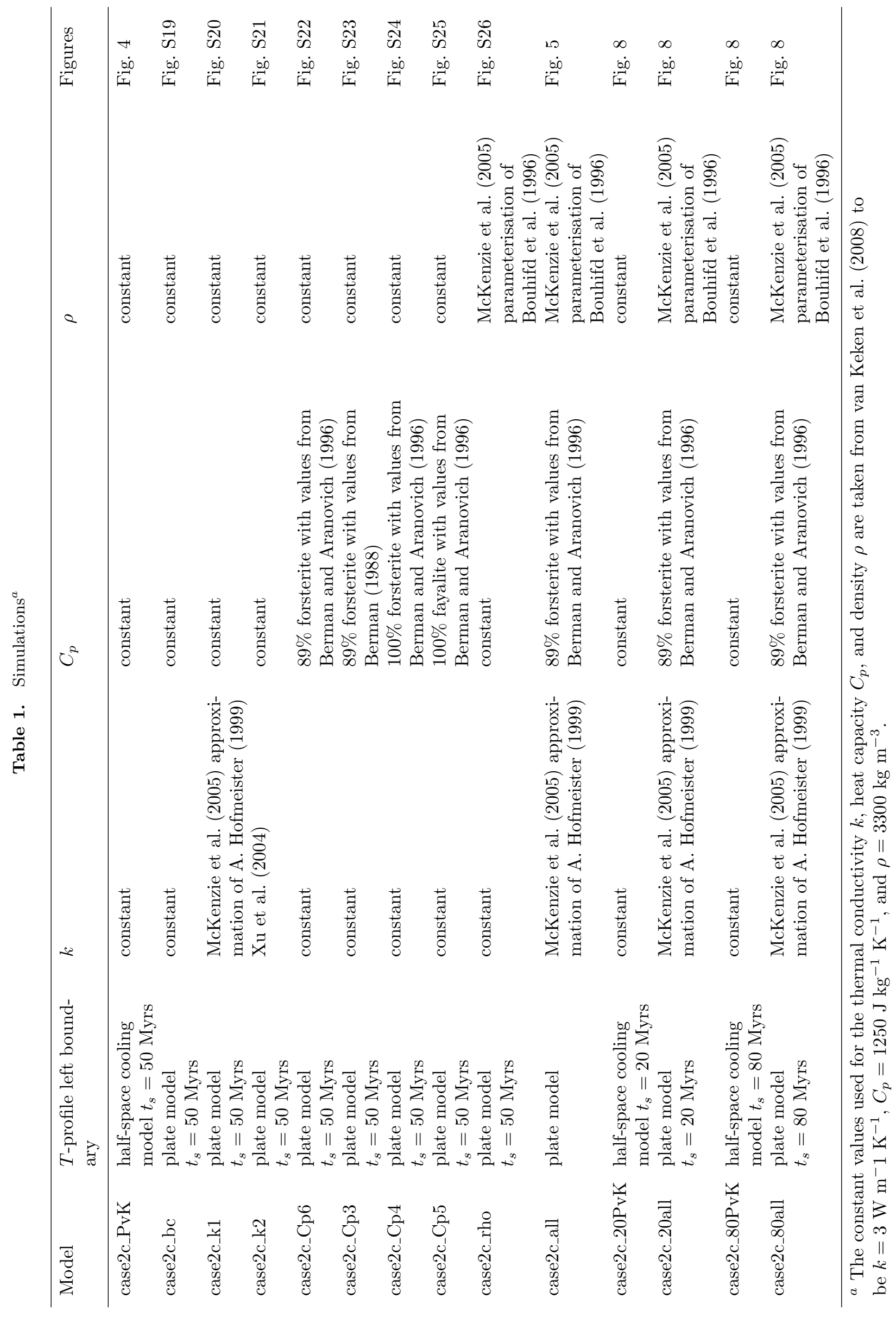




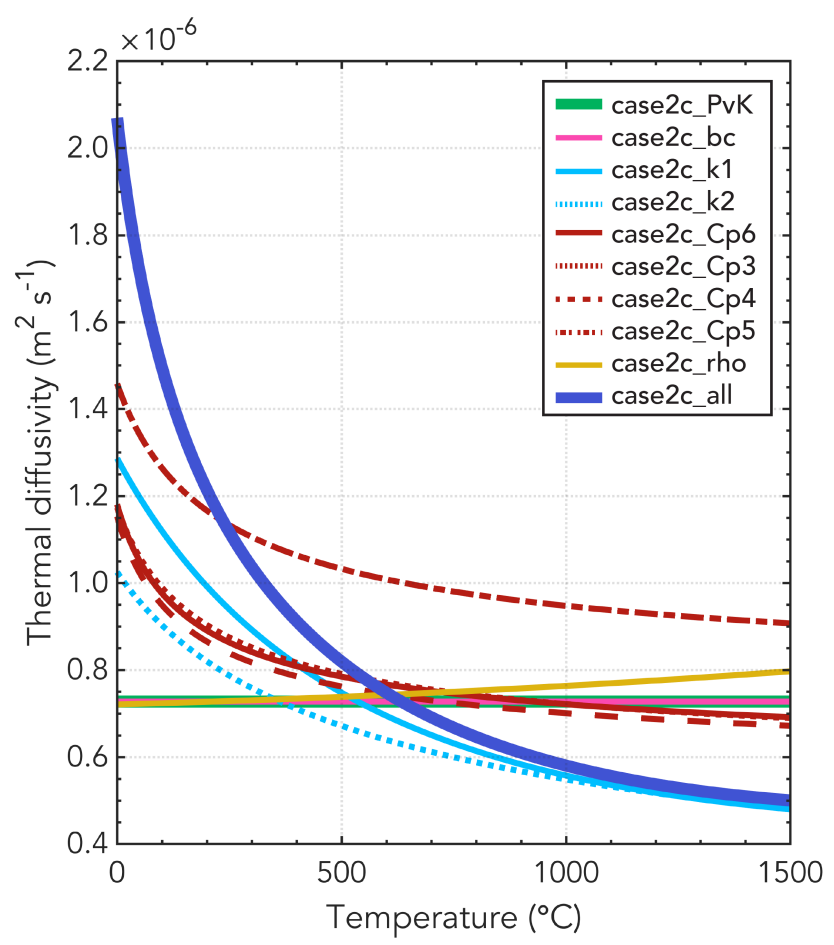

Figure 3. The thermal diffusivity $\kappa$ for all the simulations (Table 1), which indicates the overall temperature-dependence of the model by combining the thermal conductivity $k$, heat capacity $C_{p}$, and density $\rho$ according to $\kappa=\frac{k}{C_{p} \rho}$.

$$
T_{\text {slab }}=\sqrt{\frac{\sum_{i=1}^{36} T_{i i}^{2}}{36}} ;
$$

and (3) the $L 2$ norm of the temperature in the tip of the mantle wedge between 54 and $120 \mathrm{~km}$ depth as defined by

$$
T_{\text {wedge }}=\sqrt{\frac{\sum_{i=10}^{21} \sum_{j=10}^{i} T_{i j}^{2}}{78}} .
$$

In addition to the diagnostics previously used in (van Keken et al., 2008), we further report additional diagnostics that relate more closely to changes in the thermal structure that impact on other process, particularly the main processes governing seismogenesis. We report the maximum depth of the $350^{\circ} \mathrm{C}$ and $450^{\circ} \mathrm{C}$ isotherms within the slab, which are associated with the brittle-ductile transition and hence the downdip limit of the seismogenic zone of megathrust seismicity (Hyndman et al., 1997; Gutscher \& Peacock, 2003). We also report the maximum depth of the $600^{\circ} \mathrm{C}$ isotherm in the slab, which, together with the $350^{\circ} \mathrm{C}$ and $450^{\circ} \mathrm{C}$ isotherms, is associated with the main dehydration reaction fronts within the slab, and the associated intermediate-depth seismicity between $70 \mathrm{~km}$ and $350 \mathrm{~km}$ depth (Peacock, 2001; Yamasaki \& Seno, 2003; Kelemen \& Hirth, 2007).

We also provide snapshots of relevant variables, such as the temperature, viscosity, and velocity. Postprocessing and visualisation is primarily done using Matlab scripts 
(available in the Zenodo directory) with additional touch-ups in Adobe Illustrator. We use scientific colour maps by Crameri (2018b); Crameri et al. (2020) to avoid visual distortion of the data and exclusion of readers with colour-vision deficiencies (Crameri, 2018a). To compare the thermal parameters and initial temperature conditions of the different models, we colour the models according to the optimal qualitative colour palette by Anton Tsitsulin (2019; retrieved: May 10, 2021).

\section{Results}

\subsection{Models with constant thermal parameters}

The results from the reference model case2c_PvK with constant thermal parameters are shown in Figure 4. It shows a subducting plate with a relatively cold core and a cold overriding plate with the base of the overriding plate that spills into the mantle wedge. There is flow in the mantle wedge around the base of the overriding plate which reaches the tip of the mantle wedge at $x=50 \mathrm{~km}$ and $y=550 \mathrm{~km}$ and heats up the subducting plate from the top.

The reference model has a combined dislocation and diffusion creep rheology in contrast to the original cases presented in van Keken et al. (2008) which are either isoviscous (Figures S1-S4), purely diffusion creep (Figure S6), or purely dislocation creep (Figure S7). Despite the difference in rheology, the model diagnostics of our reference model do not change significantly with respect to the model with a pure dislocation or diffusion creep rheology presented in van Keken et al. (2008) (Figure S5). However, looking at the snapshots presented in Figure 4 and comparing them to the benchmark models of van Keken et al. (2008) (Figure S6,7), there are distinct differences between our reference model and the benchmark cases presented in van Keken et al. (2008) in terms of the viscosity and velocity field in the mantle wedge, as well as the temperature field within the slab. These differences are not evident from our quantitative model diagnostics, as the differences manifest themselves at high temperatures in the mantle wedge. These high temperatures and the region of the mantle wedge are not included in our model diagnostics, as they principally affect the area of the model domain outside the main focus of our study, i.e., the slab.

In model case2c_bc, we build upon our reference model and change the initial and boundary temperature condition of the subducting oceanic plate at the left of the model from a half-space cooling model to the plate model. This does not incur major changes in the model diagnostics (Table 2), consistent with the similarity between the temperature profiles of the half-space cooling model and the plate model with constant values for the thermal parameters (Figure 1b).

\subsection{Models with temperature-dependent thermal conductivity}

Using the temperature-dependent thermal conductivity according to A. Hofmeister (1999); McKenzie et al. (2005) in model case2c_k1 results in an overall colder model with the slab isotherms penetrating deeper into the mantle. This effect increases with temperature with the $350^{\circ} \mathrm{C}$ isotherm reaching $20 \mathrm{~km}$ deeper into the mantle and the $600^{\circ} \mathrm{C}$ isotherm reaching almost $90 \mathrm{~km}$ deeper into the mantle compared to the reference model (Figure 7). We observe a similar but less-pronounced trend when we use the thermal conductivity by $\mathrm{Xu}$ et al. (2004).

\subsection{Models with temperature-dependent heat capacity}

When using a temperature-dependent heat capacity, the model diagnostics show larger temperatures in the mantle wedge compared to the reference model with a constant heat capacity value. Similarly, the subducting slab is warmer and isotherms pen- 

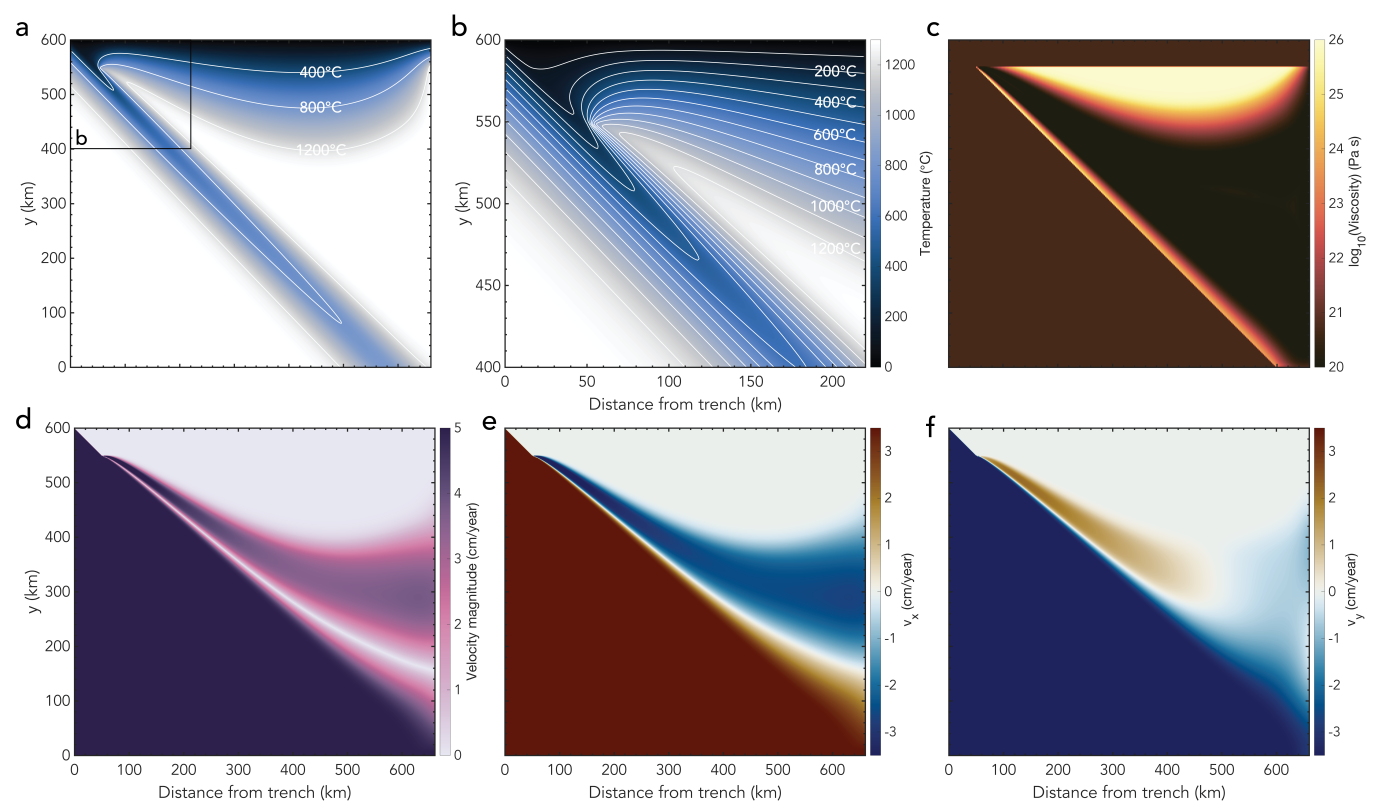

Figure 4. Snapshots of different variables for model case2c_PvK with constant values for the thermal parameters based on van Keken et al. (2008) but including both a dislocation and diffusion creep rheology (Table 1). (a) Temperature field with isotherms indicated in white; (b) zoom of the temperature field; (c) viscosity; (d) velocity magnitude; (e) horizontal component of the velocity; (f) vertical component of the velocity.

etrate less deep into the mantle. For our preferred heat capacity model with $89 \%$ forsterite and values from Berman and Aranovich (1996), the temperature diagnostics in the mantle wedge are larger by up to $37.7^{\circ} \mathrm{C}$ and the maximum depths reached by the isotherms in the slab are shallower by $13.7-50 \mathrm{~km}$ (Figure 7).

Using the values of Berman (1988) instead of the updated values of Berman and Aranovich (1996) only incurs minor changes in the model diagnostics of maximum $0.9^{\circ} \mathrm{C}$ and $1.3 \mathrm{~km}$. Changing the ratio of forsterite and fayalite to $100 \%$ forsterite in model case2c_Cp4 results in a slightly warmer mantle wedge by up to $2.8^{\circ} \mathrm{C}$ and shallower slab isotherms identical to the isotherm depths obtained in model case2c_Cp3 with values from Berman (1988) (Figure 7). In the purely fayalite model case2c_Cp5, the heat capacity is significantly lower, resulting in the model that is cooler than the model with $89 \%$ forsterite (case2c_Cp6), but still warmer than the reference model with a constant value for the heat capacity. Disregarding the temperature-dependent aspect of heat capacity tested, the overall magnitudes of the heat capacity used in the four $C_{p}$ models from Figure $2 \mathrm{~b}$ also differs. For example, the pure fayalite heat capacity model has the lowest overall heat capacity. This trend in changing magnitude of the heat capacity is also consistently visible in the model results with models with lower heat capacity exhibiting lower temperatures and models with higher heat capacity resulting in higher temperature diagnostics. However, it is not straightforward to include the model with constant heat capacity values in this trend as well. For example, model case2c_Cp5 with fayalite values consistently has a lower heat capacity than the reference model with constant values, but the overall model diagnostics still show larger temperatures like the models with both larger and smaller heat capacity magnitudes depending on the temperature. Hence, the temperature-dependence of the heat capacity has non-linear effects on the resulting temperature field. 

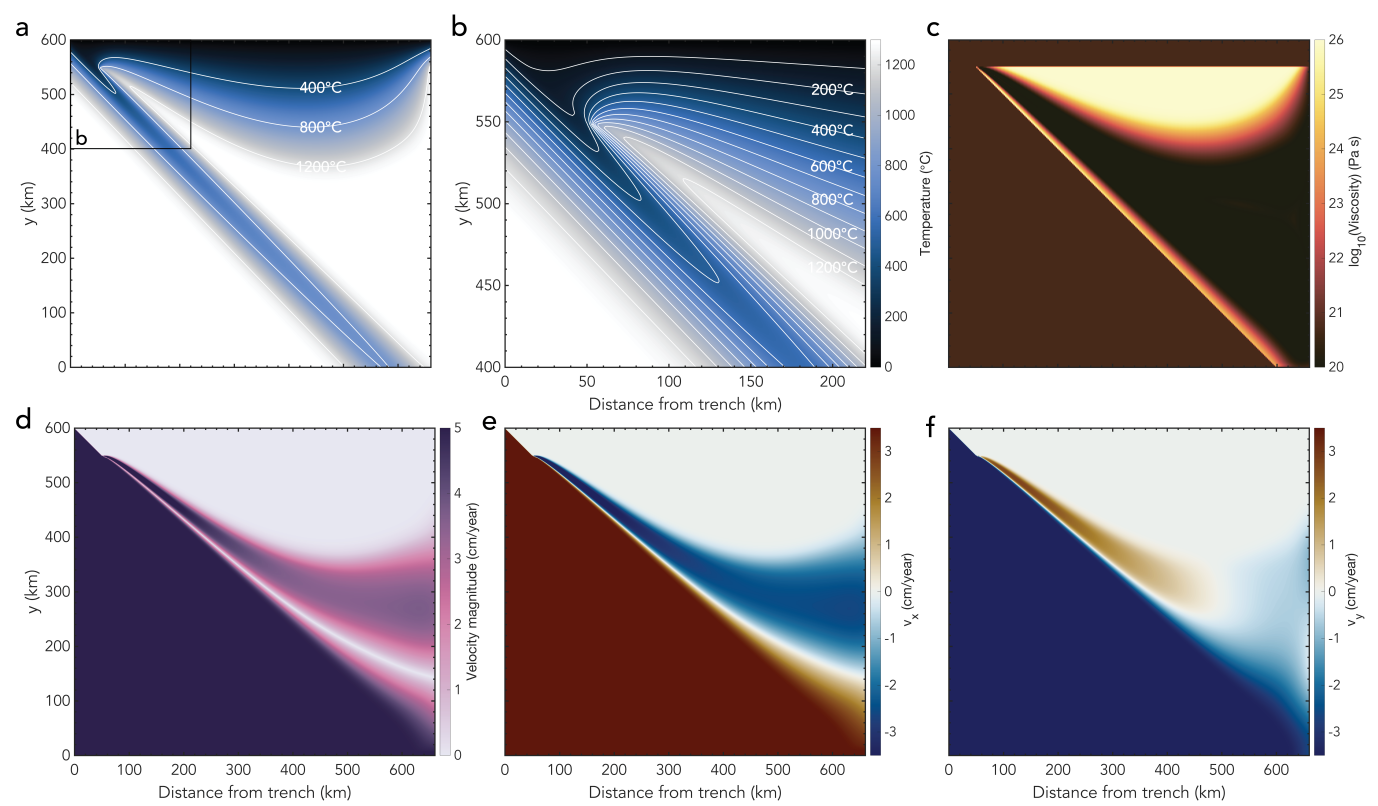

Figure 5. Snapshots of different variables for model case2c_all with our preferred temperature-dependent functions for all thermal parameters $k, C_{p}$, and $\rho$ (Table 1). (a) Temperature field with isotherms indicated in white; (b) zoom of the temperature field; (c) viscosity; (d) velocity magnitude; (e) horizontal component of the velocity; (f) vertical component of the velocity.

\subsection{Models with temperature-dependent density}

When we use a temperature-dependent density in model case2c_rho the model is cooler than the reference model case2c_PvK, but the effect is less pronounced than for the thermal conductivity (Table 2; Figure 7). This results in isotherms that reach deeper into the mantle.

\subsection{Models including all three temperature-dependent thermal param- eters}

We show the results for the model case2c_all in Figure 5. In this model, we include the temperature-dependent function for the thermal conductivity by A. Hofmeister (1999); McKenzie et al. (2005), the function of the heat capacity for $89 \%$ forsterite with values from Berman and Aranovich (1996), and the temperature-dependent density. We show the differences between this model and the reference model (Figure 4) in Figure 6 for easy comparison. Based on our model diagnostics (Table 2), the model is overall colder than the reference model and the slab has a colder core with isotherms that reach deeper into the mantle when we use temperature-dependent expressions for all thermal parameters (Figure 7). However, the effect is less pronounced than for the models where we only use a temperature-dependent expression for the thermal conductivity. This is likely because the warming effect of the temperature-dependent heat capacity cancels part of the cooling effect of using temperature-dependent thermal conductivity and density. The largest difference between the two models is due to the overriding plate, which is colder in the temperature-dependent model. Although we specifically focus on the change in thermal structure in the slab in this work, the extreme effect in the overriding plate indirectly affects the thermal structure of the slab. Since the overriding plate is colder in models including temperature-dependence of the thermal parameters, the heating of the inter- 
a

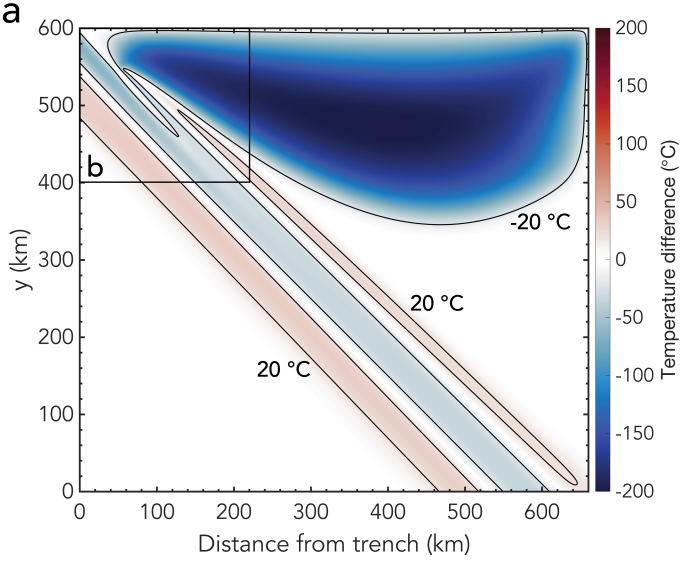

b

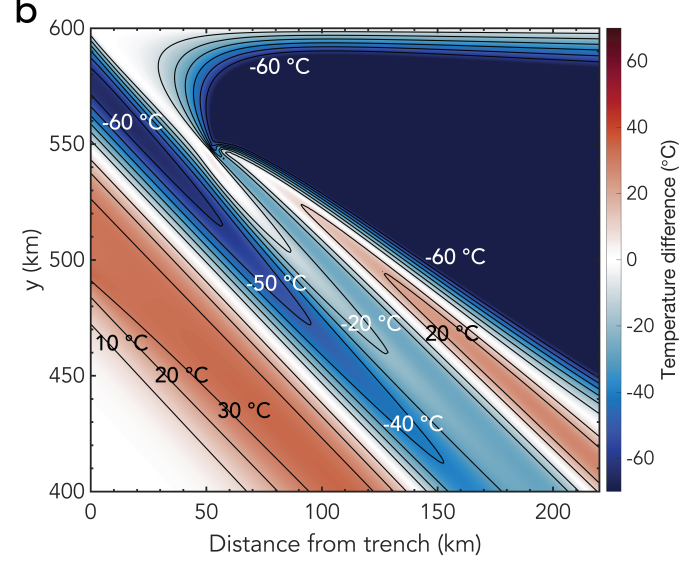

Figure 6. (a) Difference in temperature field between model case2c_all (Figure 5) and model case2c_PvK (Figure 4) with (b) a zoom of the top left corner of the model. Contours of the temperature difference are indicated in black. Note that panel (b) has a different colour scale than panel (a) to highlight the differences between the two models within the slab.

face between the slab and the overriding plate will be delayed, which will likely play an important role in time-dependent models of the thermal evolution of slab dynamics. Within the slab itself, Figure 6 shows that the largest temperature differences are approximately $-65^{\circ} \mathrm{C}$ in the shallow part. The top of the slab is colder in model case2c_all, allowing isotherms to reach deeper into the mantle. The difference in isotherm depth is $3.8 \mathrm{~km}$ for the $350^{\circ} \mathrm{C}$ isotherm, $10 \mathrm{~km}$ for the $450^{\circ} \mathrm{C}$ isotherm, and $28.8 \mathrm{~km}$ for the $600^{\circ} \mathrm{C}$ isotherm (Figure 7). At the base of the lithosphere the bottom of the slab is warmer by up to $35^{\circ} \mathrm{C}$ compared to the reference model.

To summarise the effect of using temperature-dependent thermal parameters for all our models with a plate age of $50 \mathrm{Myr}$, we plot the maximum depth of the $350^{\circ} \mathrm{C}$, $450^{\circ} \mathrm{C}$, and $600^{\circ} \mathrm{C}$ isotherms for each model in Figure 7. With respect to the reference model with constant values, adding the temperature-dependent thermal conductivity by A. Hofmeister (1999); McKenzie et al. (2005) results in the largest changes in isotherm depth, with the isotherms reaching greater depths. Using a temperature-dependent density also results in a colder top of the slab with deeper isotherms. In contrast, using a temperature-dependent heat capacity yields a warmer slab with isotherms penetrating the mantle less deep than the reference model. Combining the effect of temperature-dependent thermal conductivity, heat capacity, and density results in an overall effect of slab cooling with the isotherms reaching greater depths.

\subsection{Models with different slab ages}

Similar to the models with a plate age of $50 \mathrm{Myr}$, we see a cooling effect in the temperaturedependent thermal models for the models with different plate ages (Figure 8), with the changes to the thermal structure of the slab more pronounced with increasing slab age. Similarly, from Figure 9, we see that there is a particularly strong trend when it comes to larger isotherms such as $600^{\circ} \mathrm{C}$ with the differences between the reference models including constant thermal parameters and the models with variable properties increasing when the plate gets older. Hence, including temperature-dependent thermal parameters has a larger effect for old, cold subducting plates. This is expected, as the functions used in this paper for temperature-dependent thermal properties (Figure 2) have 
Table 2. Model diagnostics for all simulations

\begin{tabular}{l|llllll}
\hline & $\begin{array}{l}T_{x=60 \mathrm{~km}} \\
\left({ }^{\circ} \mathrm{C}\right)\end{array}$ & $\begin{array}{l}T_{\text {slab }} \\
\left({ }^{\circ} \mathrm{C}\right)\end{array}$ & $\begin{array}{l}T_{\text {wedge }} \\
\left({ }^{\circ} \mathrm{C}\right)\end{array}$ & $\begin{array}{l}\text { Max depth } \\
350^{\circ} \mathrm{C}(\mathrm{km})\end{array}$ & $\begin{array}{l}\text { Max depth } \\
450^{\circ} \mathrm{C}(\mathrm{km})\end{array}$ & $\begin{array}{l}\text { Max depth } \\
600{ }^{\circ} \mathrm{C}(\mathrm{km})\end{array}$ \\
\hline case2c_PvK & 578.5 & 604.9 & 999.5 & 77.5 & 110.0 & 203.8 \\
case2c_bc & 578.4 & 604.8 & 999.5 & 77.5 & 110.0 & 203.8 \\
case2c_k1 & 526.0 & 553.6 & 948.9 & 97.5 & 148.8 & 291.3 \\
case2c_k2 & 549.8 & 573.0 & 975.3 & 90.0 & 135.0 & 260.0 \\
case2c_Cp6 & 616.2 & 642.4 & 1007.6 & 63.8 & 87.5 & 153.8 \\
case2c_Cp3 & 616.9 & 643.3 & 1007.8 & 63.8 & 86.3 & 152.5 \\
case2c_Cp4 & 618.9 & 644.0 & 1010.4 & 63.8 & 86.3 & 152.5 \\
case2c_Cp5 & 588.4 & 626.1 & 979.0 & 66.3 & 91.3 & 161.3 \\
case2c_rho & 566.6 & 593.7 & 992.0 & 81.3 & 117.5 & 221.3 \\
case2c_all & 552.6 & 581.6 & 949.8 & 81.3 & 120.0 & 232.5 \\
case2c_20PvK & 631.8 & 670.6 & 1008.6 & 53.8 & 70.0 & 108.8 \\
case2c_20all & 602.9 & 643.9 & 957.9 & 78.8 & 97.5 & 125.0 \\
case2c_80PvK & 558.5 & 578.9 & 996.0 & 97.5 & 148.8 & 293.8 \\
case2c_80all & 533.6 & 556.9 & 946.6 & 102.5 & 162.5 & 333.8 \\
\hline
\end{tabular}

their most extreme values at lower temperatures, which are more prevalent in older, and hence colder, slabs.

\section{Discussion}

Our results clearly show that temperature-dependent thermal parameters significantly affect the thermal structure of the slab in these simple models of subduction zones. Our models with different plate ages show that the implications generalise to all subduction zones regardless of plate age, but they still lack realism in terms of model geometry and the inclusion of many important processes relevant for the development of a realistic thermal structure of the slab.

In this section, we first discuss the implications of our results on modelling the thermal structure of subduction zones in light of megathrust, intermediate-depth, and deep seismicity while taking into account the simple nature of our models (Section 4.1). As our models are conceptual calculations for the impact of including temperature-dependent variables, these implications are generic, rather than applicable directly to any given subduction zone (van Zelst et al., 2021). We further discuss the potential implications of our thermal models for the geochemical and mineralogical evolution of the slab, and the impact this may have on the flux of fluids through subduction zones (Section 4.2). We then discuss how realistic our models are, their limitations, and how future work could improve both the models, and their applicability (Section 4.3).

\subsection{Implications for seismicity}

The temperature structure of a slab determines to a large extent where seismicity is expected to occur, through its effect on both the mode of failure and the onset of ductility, and its control on geochemical transitions within the slab and along the megathrust interface, including dehydration reactions. Here we summarise those effects and highlight how the results presented in Section 3 translate to influences on the distribution and extent of intermediate-depth and deep-focus earthquakes, and potentially on the extent of megathrust and related shallow seismicity. 


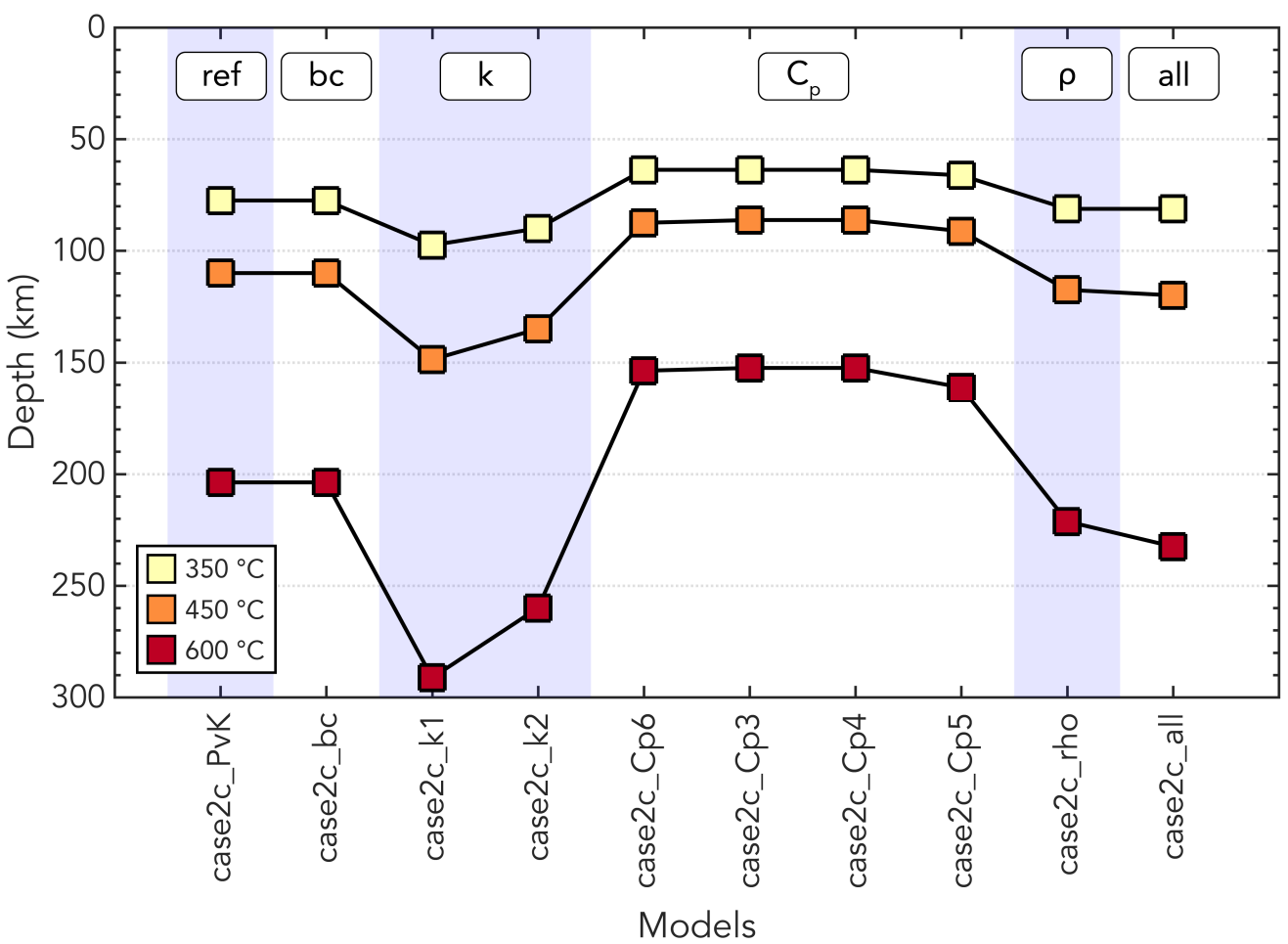

Figure 7. Change in maximum isotherm depth within the slab for models with different variations of temperature-dependent thermal parameters (Table 1). The three isotherm depths plotted here are the same as the ones from the model diagnostics in Table 2. Different groups of models (i.e., testing different functions for the temperature-dependence of the thermal conductivity $k$ ) are indicated by vertical bands for clarity. Here, 'ref' refers to the reference model case2c_PvK.

\subsubsection{Intermediate-depth seismicity}

Although the shallow slab geometry in our model is clearly a simplification, at depths consistent with intermediate-depth seismicity, the slab dip of $45^{\circ}$ in our models is realistic, with an average slab dip of $45.5^{\circ}$ reported by Syracuse et al. (2010) in nature, although it remains highly variable between different subduction zones. Other studies also find that the slab dip is steeper away from the interface between the slab and the overriding plate (e.g., Jarrard, 1986; King, 2001; Hu \& Gurnis, 2020). Therefore, we can make some inferences on the expected depth of intermediate-depth seismicity using our models. Intermediate-depth seismicity at depths of $75-300 \mathrm{~km}$ is commonly associated with a temperature range between $600^{\circ} \mathrm{C}$ and $800^{\circ} \mathrm{C}$, where dehydration embrittlement of the metamorphosed minerals in the slab occurs (e.g., Jung et al., 2004; Wang et al., 2017). Focusing on the $600^{\circ} \mathrm{C}$ isotherm in our models (Table 2; Figure 7), we see that its depth changes significantly throughout our parameter space with a depth of $203.8 \mathrm{~km}$ for the reference model case2c_PvK, $232.5 \mathrm{~km}$ for model case2c_all, and end members of $291.3 \mathrm{~km}$ depth for model case2c_k1 and $152.5 \mathrm{~km}$ depth for models case2c_Cp3 and case2c_Cp4. Hence, the depth at which dehydration reactions are expected to occur varies by almost $140 \mathrm{~km}$ within our parameter space. Therefore, the predicted depth of intermediate-depth seismicity in thermal models of subduction should be viewed in light of the assumptions on the thermal parameters. In addition, previous thermal models (e.g., Syracuse et al., 2010; Van Keken et al., 2012) that use constant values for the thermal parameters and reproduce a thermal structure that fits observed seismicity are expected to change when 

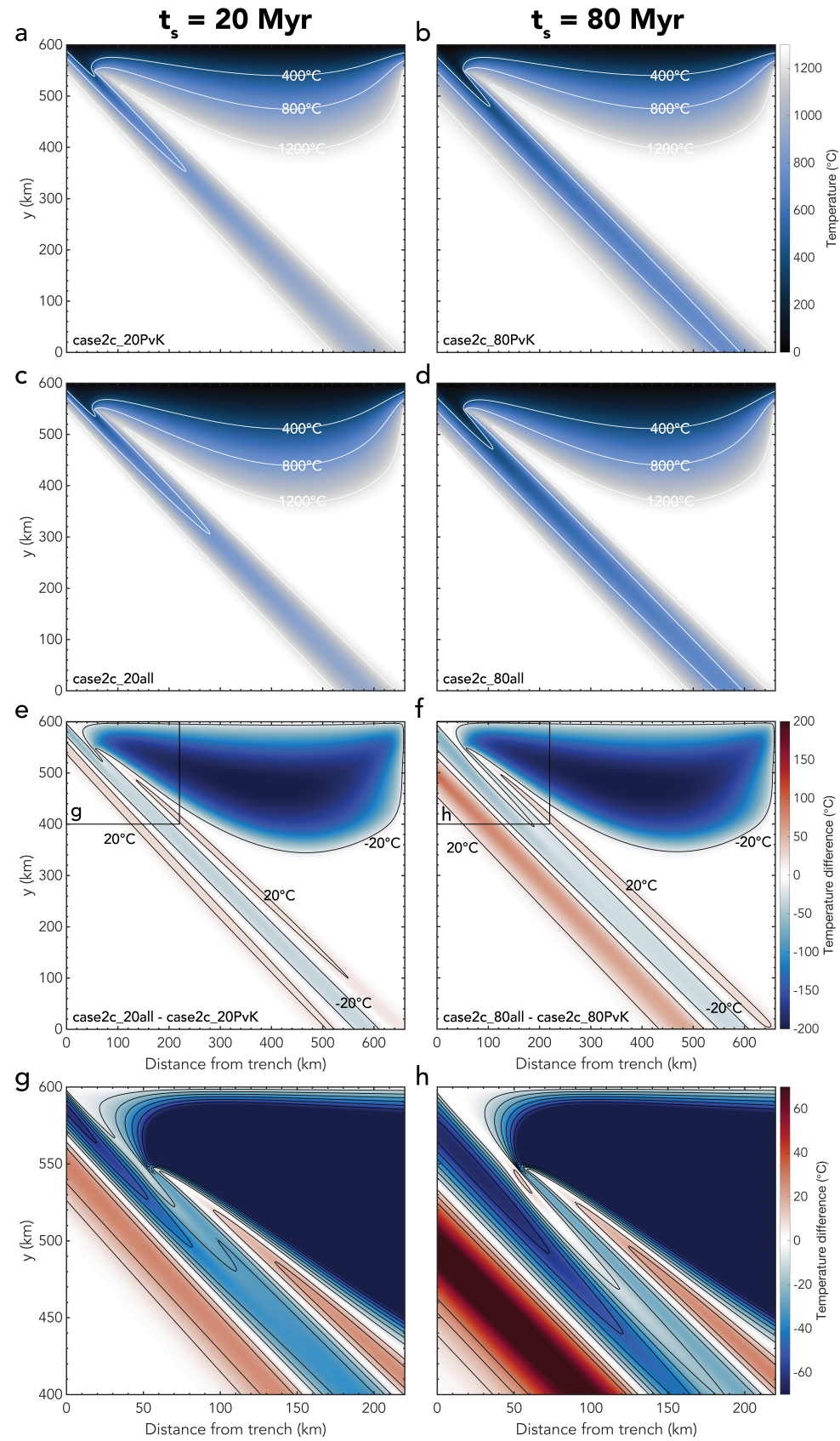

Figure 8. (a-d) Snapshots of the temperature field for models with a slab age of (a,c) $20 \mathrm{Myr}$ and (b,d) 80 Myr with (a,b) constant and (c,d) variable thermal parameters (Table 1). (e-h) Difference in temperature field between $(\mathrm{e}, \mathrm{g})$ model case2c_20all and model case2c_20PvK with (g) a zoom of the top left corner of the model. (f,h) Same as panel (e,g) but for a slab age of 80 Myr. Contours of the temperature difference are indicated in black. In panels $(\mathrm{g}, \mathrm{h})$ contours for every $10^{\circ}$ temperature difference are drawn. Note that panels $(\mathrm{g}, \mathrm{h})$ have a different colour scale than panel $(\mathrm{e}, \mathrm{f})$ to highlight the differences between the two models within the slab and to easily compare to Figure 6. 


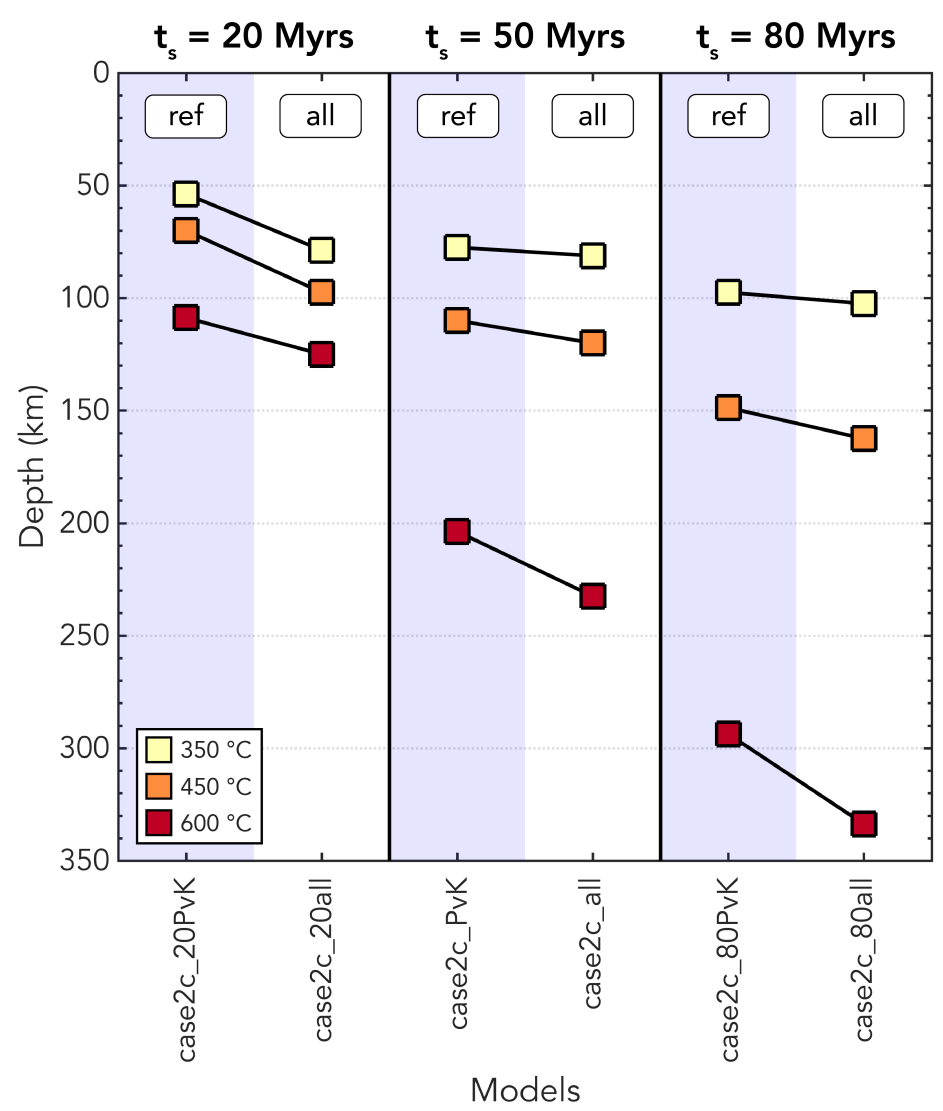

Figure 9. Change in maximum isotherm depth within the slab for end-member models with different subducting plate ages (Table 1). The three isotherm depths plotted here are the same as the ones from the model diagnostics in Table 2. The models with constant values are indicated by 'ref'.

temperature-dependent thermal parameters are used, with implications for the thermochemical changes then ascribed to control intermediate depth seismicity. Depending on the choices of the functions describing the thermal parameters and their interaction, the fit with observed seismicity can change. To accurately determine the depth of intermediatedepth seismicity and the relationship between the thermal structure of the slab and intermediatedepth seismicity, we recommend the use of temperature-dependent thermal parameters constrained by the insights on rock behaviour. Neglecting temperature-dependent thermal parameters could result in significant errors of up to hundreds of kilometres in the estimated depth of intermediate-depth seismicity or a misinterpretation of the relation between the thermal structure of a slab and observed intermediate-depth seismicity.

\subsubsection{Deep seismicity}

The cause of deep earthquakes $(>300 \mathrm{~km})$ is hotly debated with proposed mechanisms such as dehydration embrittlement, transformational faulting, and (grain size assisted) thermal runway as a result of shear heating (see Green \& Houston, 1995; Frohlich, 2006; Zhan, 2020, for an overview). Regardless of the exact mechanism responsible for deep earthquakes, it is clear that the thermal structure of the slab plays a large role through providing the optimal conditions for each of these mechanisms to occur in. In fact, recent studies by Jia et al. (2020); Liu et al. (2021) have shown that local slab tempera- 
ture likely controls the rupture of deep earthquakes. Our results show that the effect of using temperature-dependent thermal parameters instead of constant values grows more pronounced with depth. Therefore, we expect that adding temperature-dependent thermal parameters will significantly affect models of the thermal structure of slabs at depths between 300-600 km relevant to deep earthquakes.

\subsubsection{Megathrust seismicity}

Our models here are of limited use in assessing the sensitivity of the temperature along the shallow interface to the inclusion of temperature-dependent thermal properties, as (a) in our simplified model geometry, the shallow dip of our interface is significantly greater than that typically seen in the interface seismogenic zone of most subduction zones (typically $23 \pm 8^{\circ}$ (e.g., Jarrard, 1986; Heuret et al., 2011; Schellart \& Rawlinson, 2013)); (b) we refrain from including the compositional complexity necessary to appropriately model the thermal structure of the overriding plate and/or a sedimentary forearc; and (c) we do not include the effects of shear heating on the shallow interface P. England (2018).

However, noting the impact that the extreme variation in thermal properties at low temperatures (e.g., Figure 3) has on the rates at which cold material will heat up near the top of the downgoing plate and in the wedge of the forearc, we recommend using temperaturedependent thermal parameters in thermal models of subduction zones, in addition to the other influences mentioned, for when physically realistic estimations of the seismogenic zone size are desired. Similarly, when observations are linked to the behaviour of the interface (e.g., limits on seismogenesis, on coupling, on slow slip, etc.), the inclusion of temperaturedependent thermal parameters may alter the inferred mineralogical and rheological controls on such transitions.

\subsection{Mineralogical evolution of the slab}

As the subducting plate descends, it typically undergoes a range of mineralogical transitions, relating to the increase in pressure and temperature. These mineralogical changes, particularly the location at which dehydration reactions may release fluids into the slab system, play a controlling role in determining the location of intraslab seismicity, and also in influencing a range of other geophysical phenomena, from the internal impedance and velocity contrasts within the slab (e.g., G. A. Abers, 2000; Rondenay et al., 2008), to the occurrence of slow slip events on the subduction interface (e.g., Peacock, 2009), to the development of a hydrated mantle forearc (e.g., G. Abers et al., 2017). The preservation of volatile-hosting lower-temperature material into the deeper mantle also plays a role in global geochemical cycles (e.g., Rüpke et al., 2004).

Whilst the kinematic constraints we impose on the slab in our models mean there is little variation in lithostatic pressure between models, we have shown that including the temperature dependence of thermal parameters in the modelling of slab thermal structures has an impact on the resultant temperature field. Whilst these changes are small relative to the total change in temperature experienced by the slab during subduction, they lead to a slightly different pressure-temperature evolution for the slab material. An additional crustal layer in our models, which is not included at the moment, would further alter the temperature field. However, we note that the changes in the temperature evolution of the uppermost $\sim 8 \mathrm{~km}$ of the slab is particularly susceptible to the temperature dependence of thermal properties, given the rapid variation of such values at cold temperatures (Figure 3). The mineralogical evolution of the shallowest part of the slab is therefore likely to be altered by the incorporation of temperature-dependent thermal properties, with initially more rapid heating at low pressures giving way to slower heating at higher pressures, in comparison to models using fixed, temperature-independent thermal properties. Dehydration reactions in hydrated basaltic oceanic crust typically 
take place between $350-450^{\circ} \mathrm{C}$, whilst those in serpentinised oceanic mantle concentrate between $600^{\circ} \mathrm{C}$ and $800^{\circ} \mathrm{C}$ (Hacker, Abers, \& Peacock, 2003). In linking geophysical observations to thermal models, we again note that the variation in depth of the $350^{\circ} \mathrm{C}$ and $450^{\circ} \mathrm{C}$ isotherms in our models of up to $38.8 \mathrm{~km}$ with respect to the reference model case2c_PvK (Figure 7) would translate for most subduction zones into a significant trenchperpendicular lateral shift. This will have a significant impact on the source location of phenomena such as the migration of fluids from the slab to the forearc mantle and/or updip along the subduction interface.

Lastly, the model diagnostics we focus on here centre around the maximum depth of a given isotherm. However, the variation in thermal structure that we study will also impact on the thermal cross section of the slab at any given depth - with marginally colder slabs having a significantly greater volume of material below a given temperature at a given depth, and hence potentially altering the volatile fluxes within slabs into the mid mantle.

\subsection{Model limitations and future work}

With the exception of a different rheology in the mantle wedge, where we combine both diffusion and dislocation creep, we use the same model setup as the subduction zone community benchmark presented by van Keken et al. (2008). We choose this model setup, as it is well constrained and documented and reproduced by many codes in the geodynamics community (see codes used in van Keken et al., 2008). Hence, we are able to study the effect of temperature-dependent thermal parameters on the thermal structure of subduction zones in an isolated, well-constrained manner, although, as discussed, this does limit their direct applicably to observational data.

The model setup is greatly simplified and many complexities that are known to influence the thermal structure of the slab are ignored. As illustrated in the benchmark of van Keken et al. (2008) itself, one of the largest influences of thermal structure of the subducting slab is the employed rheology. The temperature model diagnostics in van Keken et al. (2008) change up to $189^{\circ} \mathrm{C}$ when changing from an isoviscous to a dislocation or diffusion creep rheology. To a lesser extent, the difference between a purely dislocation creep and diffusion creep rheology is noticeable with variations on the order of $10^{\circ} \mathrm{C}$ in model diagnostics. We find that employing a combined dislocation and diffusion creep rheology does not significantly change the model diagnostics compared to a purely dislocation or diffusion creep rheology. However, our approximation of combining a dislocation and diffusion creep rheology is simplistic. Using a composite rheology of diffusion and dislocation creep to properly account for the nonlinearity of the two rheologies would be more physically appropriate (Ranalli, 1995; Karato, 2008; T. Gerya, 2019). This would likely introduce changes to the temperature field of the slab on the same order as the differences observed between a pure diffusion and a pure dislocation model as in van Keken et al. (2018).

Hence, the effect of using temperature-dependent thermal parameters in thermal models instead of constant values is a secondary effect to rheology when comparing isoviscous and non-linear rheologies. However, when comparing non-linear rheologies, using temperature-dependent thermal parameters instead of constant values will likely have a greater effect on the thermal structure of the slab than changing the details of the rheology formulation. Note that these conclusions relate to the thermal structure of the slab; the rheology plays a major role in the thermal structure of the mantle wedge and overriding plate, as evident from the original benchmarks presented in van Keken et al. (2008).

Apart from a simplified rheology, we also employ a simplified geometry in our model setup. Although the model serves as a good benchmark and we can infer some implications for seismicity from this simple setup, a strictly $45^{\circ} \mathrm{C}$ dipping slab is not realistic. In nature the slab dip changes with depth with low dipping angles of $23 \pm 8^{\circ}$ for the megath- 
rust (Heuret et al., 2011) and larger dip at depth (e.g., Isacks \& Barazangi, 1977; King, 2001; Cruciani et al., 2005; Syracuse et al., 2010; Klemd et al., 2011; Hu \& Gurnis, 2020). Therefore, more realistic models of the thermal structure of subduction zones include these complex geometries (e.g., Syracuse et al., 2010; Van Keken et al., 2012). Our results indicate that in these complex models of the thermal structure of the slab, it is important to take the temperature-dependence of thermal parameters into account as well. Even though including them will likely not change the large-scale subduction evolution, it is important to include the temperature-dependent thermal parameters for accurate comparison with (earthquake) data.

Although we focus here on the effect of using temperature-dependent thermal parameters, there are numerous other processes relevant to the developing thermal structure of a subduction zone (see van Keken et al., 2019, for an overview). For example, frictional (or shear) heating along the plate interface (e.g., Peacock, 1992; Peacock \& Wang, 1999; Gao \& Wang, 2014, 2017) and radiogenic heating in the overriding plate (e.g., Gao \& Wang, 2014; P. England, 2018) introduce an additional heat source to the system and result in warmer slabs in line with petrological estimates of the temperatures of rocks in a subduction zone (Penniston-Dorland et al., 2015). Typically these processes are included in models where a temperature-dependent density formulation is used, although the conductivity and heat capacity are often still taken to be constants. We deliberately do not include these additional heat sources when including the temperature-dependent density to isolate its effect on the thermal structure of a subduction zone. However, we recognise that this may lead to thermodynamic inconsistencies, similar to those introduced through inconsistent thermodynamic potentials calculated from the thermal parameters (Schubert et al., 2001; van Zelst et al., 2021). Phase changes, such as serpentinisation in the mantle wedge corner (e.g., Hyndman \& Peacock, 2003) and the transition from blueschist to hydrous eclogite (e.g., Hacker, Abers, \& Peacock, 2003), also play an important role in establishing the thermal structure of the slab, as they are paired with the release of latent heat, density and subsequent volume changes, fluid production and heat advection (see Peacock, 2020, for an overview of petrologic models). Fluid flow and hydrothermal circulation within the upper part of the slab efficiently transport heat updip towards the trench (e.g., Spinelli \& Wang, 2008; P. C. England \& Katz, 2010; Faccenda et al., 2012; Rotman \& Spinelli, 2013; R. N. Harris et al., 2017). Depending on the subduction velocity, this can significantly reduce the temperature of the subduction interface (Rotman \& Spinelli, 2013). In line with this, processes such as melting and melt transport at the top of the slab and in the mantle wedge corner (e.g., P. C. England \& Katz, 2010; Bouilhol et al., 2015; Perrin et al., 2016), magmatism (e.g., Jones et al., 2018), erosion (e.g., Royden, 1993; P. England, 2018), sedimentation (e.g., P. England, 2018), and three-dimensional complexities (e.g., T. V. Gerya, 2011; Wada, 2021) also play a role in the thermal structure of a subduction zone. In addition, subduction is an inherently time-dependent process with the temperature structure of the subducting slab likely changing throughout its evolution which is not captured by the steady-state thermal models presented here (King, 2001; Holt \& Condit, 2021). Here, we deliberately choose to ignore these complexities to isolate the effect of temperature-dependent thermal parameters on the thermal structure of the slab. Future studies could focus on these processes to explore their effect on models of the thermal structure of the slab.

Lastly, there are numerous functions describing the temperature-dependence of the thermal parameters in the literature and existing functions are continuously updated with improved values for constants to better fit laboratory data. It is outside of the scope of this work to test all different formulations and here we follow McKenzie et al. (2005) and Richards et al. (2018) who used temperature-dependent thermal parameters for plate models of the cooling oceanic lithosphere. However, other possible functions of the temperaturedependence of thermal parameters include formulations from studies like e.g., Berman and Brown (1985); Seipold (1998); A. M. Hofmeister (2007b); Wen et al. (2015); Su et al. (2018). 
In addition, the thermal parameters do not merely depend on temperature, but are also dependent on pressure (A. M. Hofmeister, 2007a). We do not consider this pressuredependence here as we kinematically prescribe the slab and hence do not solve for pressure or velocity within the slab. Studies of the thermal structure of cooling oceanic lithosphere show that the residual misfit with the data reduces upon including the pressuredependence of the thermal parameters (e.g., Grose \& Afonso, 2013; Korenaga \& Korenaga, 2016; Richards et al., 2018).

We also restrict our models to a single composition only. We do not include a crustal layer, and we neglect the impact that the mineralogical evolution of the slab will have on the temperature structure, both through the variation in thermal parameters with evolving mineralogy, and through the latent heat of mineralogical transformation.

\section{Conclusions}

In this work, we look at the effect of adding temperature-dependent thermal parameter in thermal models of subduction zones compared to using constant values.

Using temperature-dependent conductivity decreases the temperature in the slab and results in a larger predicted seismogenic zone width and deeper intermediate-depth seismicity with the maximum depth of the $600^{\circ} \mathrm{C}$ isotherm changing up to $87.5 \mathrm{~km}$ for a model using the thermal conductivity function of (A. Hofmeister, 1999; McKenzie et al., 2005) compared to a reference models with constant values.

Employing a temperature-dependent heat capacity has the opposite effect and results in a warmer slab with a shallower downdip limit of the seismogenic zone and predicted depth of dehydration reactions responsible for intermediate-depth seismicity.

A temperature-dependent density has the least effect on the thermal structure of the slab when compared to the reference model with constant values, although the slab is overall colder. Combining the temperature-dependence of the three thermal parameters negates the effect on the thermal structure of the slab slightly, but the strong cooling of the slab produced by both the temperature-dependent thermal conductivity and density dominates. Therefore, the modelled slab is colder than a slab modelled with constant thermal parameters with, e.g., the maximum depth of the $600^{\circ} \mathrm{C}$ isotherm changing by $28.8 \mathrm{~km}$. The importance of including temperature-dependent thermal parameters increases for increasing slab age, as the functions of the thermal parameters used in this paper have their most extreme values for lower temperatures.

Even considering the simplifications in our model setup, our results indicate that the changes in the modelled thermal structure of the slab will have important implications on the estimated size of the seismogenic zone in these kinds of thermal models and predictions where intermediate-depth seismicity might occur. For optimal comparison to data and to avoid misinterpretations, we therefore recommend that temperature-dependent thermal parameters are an important modelling ingredient and should be taken into account when using thermal(-mechanical) models of subduction zones.

\section{Acknowledgements}

We thank Peter van Keken for providing the original data from van Keken et al. (2008) used to benchmark the code presented here and for providing additional insights on the model setup.

Elements of this work were undertaken on ARC4, part of the High Performance Computing facilities at the University of Leeds, UK. IvZ and TJC were funded by the Royal Society (UK) through University Research Fellowship URF $\backslash$ R1 $\backslash 180088$ and Research Fellows Enhancement Award RGF $\backslash \mathrm{EA} \backslash 181084$. TJC was also supported through 
COMET, the UK Natural Environment Research Council's Centre for the Observation and Modelling of Earthquakes, Volcanoes, and Tectonics.

\section{Author contribution statement}

IvZ and TJC conceived the study. IvZ designed and ran the models, analysed the results, and wrote the article. CT and IvZ wrote the code xFieldstone. TJC supervised IvZ and contributed to the analysis of the models. All authors discussed the results and contributed to the model design and the final manuscript.

\section{Data availability statement}

The models were run with the open source xFieldstone (which will be made available on github upon publication). The exact version of the code will be stored in a Zenodo repository. In this repository the data used to reproduce the van Keken et al. (2008) benchmark, the raw data used to produce the figures in this article and the matlab postprocessing scripts can be found as well.

\section{References}

Abers, G., Van Keken, P., \& Hacker, B. (2017). The cold and relatively dry nature of mantle forearcs in subduction zones. Nature Geoscience, 10(5), 333-337.

Abers, G. A. (2000). Hydrated subducted crust at 100-250 km depth. Earth and Planetary Science Letters, 176(3-4), 323-330.

Abers, G. A., van Keken, P. E., Kneller, E. A., Ferris, A., \& Stachnik, J. C. (2006). The thermal structure of subduction zones constrained by seismic imaging: Implications for slab dehydration and wedge flow. Earth and Planetary Science Letters, $241(3-4), 387-397$.

Anton Tsitsulin. (2019; retrieved: May 10, 2021). Optimal qualitative colour palettes. (http://tsitsul.in/blog/coloropt/)

Arcay, D. (2017). Modelling the interplate domain in thermo-mechanical simulations of subduction: Critical effects of resolution and rheology, and consequences on wet mantle melting. $\quad$ Physics of the Earth and Planetary Interiors, 269, $112-132$.

Beall, A., Fagereng, Å., Davies, J. H., Garel, F., \& Davies, D. R. (2021). Influence of subduction zone dynamics on interface shear stress and potential relationship with seismogenic behavior. Geochemistry, Geophysics, Geosystems, 22(2), e09267.

Berman, R. G. (1988). Internally-consistent thermodynamic data for minerals in the system na2o-k2o-cao-mgo-feo-fe2o3-al2o3-sio2-tio2-h2o-co2. Journal of petrology, 29(2), 445-522.

Berman, R. G., \& Aranovich, L. Y. (1996). Optimized standard state and solution properties of minerals: I. Model calibration for olivine, orthopyroxene, cordierite, garnet, and ilmenite in the system FeO-MgO-CaO-Al2O3-TiO2SiO2. Contributions to Mineralogy and Petrology, 126(1), 1-24.

Berman, R. G., \& Brown, T. H. (1985). Heat capacity of minerals in the system na 2 ok 2 o-cao-mgo-feo-fe 2 o 3 -al 2 o 3-sio 2-tio 2-h 2 o-co 2 : representation, estimation, and high temperature extrapolation. Contributions to Mineralogy and Petrology, 89(2), 168-183.

Blom, N., Boehm, C., \& Fichtner, A. (2017). Synthetic inversions for density using seismic and gravity data. Geophysical Journal International, 209(2), 12041220 .

Bouhifd, M. A., Andrault, D., Fiquet, G., \& Richet, P. (1996). Thermal expansion of forsterite up to the melting point. Geophysical research letters, 23(10), 11431146. 
Bouilhol, P., Magni, V., van Hunen, J., \& Kaislaniemi, L. (2015). A numerical approach to melting in warm subduction zones. , 411, 37-44.

Brizzi, S., van Zelst, I., Funiciello, F., Corbi, F., \& van Dinther, Y. (2020). How sediment thickness influences subduction dynamics and seismicity. Journal of Geophysical Research: Solid Earth, 125(8), e2019JB018964.

Chang, C., McNeill, L. C., Moore, J. C., Lin, W., Conin, M., \& Yamada, Y. (2010). In situ stress state in the Nankai accretionary wedge estimated from borehole wall failures. Geochemistry, Geophysics, Geosystems, 11(12).

Crameri, F. (2018a). Geodynamic diagnostics, scientific visualisation and StagLab 3.0. Geoscientific Model Development, 11(6), 2541-2562.

Crameri, F. (2018b). Scientific colour-maps. Zenodo. Retrieved from http://doi . org/10.5281/zenodo.1243862 doi: http://doi.org/10.5281/zenodo.1243862

Crameri, F., Shephard, G. E., \& Heron, P. J. (2020). The misuse of colour in science communication. Nature communications, 11(1), 1-10.

Crosby, A., McKenzie, D., \& Sclater, J. (2006). The relationship between depth, age and gravity in the oceans. Geophysical Journal International, 166(2), 553573.

Cruciani, C., Carminati, E., \& Doglioni, C. (2005). Slab dip vs. lithosphere age: no direct function. Earth and Planetary Science Letters, 238(3-4), 298-310.

Denlinger, R. P. (1992). A revised estimate for the temperature structure of the oceanic lithosphere. Journal of Geophysical Research: Solid Earth, 97(B5), $7219-7222$.

Emmerson, B., \& McKenzie, D. (2007). Thermal structure and seismicity of subducting lithosphere. Physics of the Earth and Planetary Interiors, 163(1-4), 191-208.

England, P. (2018). On shear stresses, temperatures, and the maximum magnitudes of earthquakes at convergent plate boundaries. Journal of Geophysical Research: Solid Earth, 123(8), 7165-7202.

England, P. C., \& Katz, R. F. (2010). Melting above the anhydrous solidus controls the location of volcanic arcs. Nature, 467(7316), 700-703.

Faccenda, M., Gerya, T. V., Mancktelow, N. S., \& Moresi, L. (2012). Fluid flow during slab unbending and dehydration: Implications for intermediate-depth seismicity, slab weakening and deep water recycling. Geochemistry, Geophysics, Geosystems, 13(1).

Frohlich, C. (2006). Deep earthquakes.

Fulton, P., Brodsky, E. E., Kano, Y., Mori, J., Chester, F., Ishikawa, T., ... others (2013). Low coseismic friction on the Tohoku-Oki fault determined from temperature measurements. Science, 342(6163), 1214-1217.

Gao, X., \& Wang, K. (2014). Strength of stick-slip and creeping subduction megathrusts from heat flow observations. Science, 345(6200), 1038-1041.

Gao, X., \& Wang, K. (2017). Rheological separation of the megathrust seismogenic zone and episodic tremor and slip. Nature, 543(7645), 416-419.

Gerya, T. (2019). Introduction to numerical geodynamic modelling. Cambridge University Press.

Gerya, T. V. (2011). Future directions in subduction modeling. Journal of Geodynamics, 52(5), 344-378.

Gerya, T. V., \& Meilick, F. (2011). Geodynamic regimes of subduction under an active margin: effects of rheological weakening by fluids and melts. Journal of Metamorphic Geology, 29(1), 7-31.

Green, H. W., \& Houston, H. (1995). The mechanics of deep earthquakes. Annual Review of Earth and Planetary Sciences, 23(1), 169-213.

Grose, C. J., \& Afonso, J. C. (2013). Comprehensive plate models for the thermal evolution of oceanic lithosphere. Geochemistry, Geophysics, Geosystems, 14(9), $3751-3778$.

Gutscher, M.-A., \& Peacock, S. M. (2003). Thermal models of flat subduction and 
the rupture zone of great subduction earthquakes. Journal of Geophysical Research: Solid Earth, 108(B1), ESE-2.

Hacker, B. R., Abers, G. A., \& Peacock, S. M. (2003). Subduction factory 1. Theoretical mineralogy, densities, seismic wave speeds, and $\mathrm{H} 2 \mathrm{O}$ contents. Journal of Geophysical Research: Solid Earth, 108(B1).

Hacker, B. R., Peacock, S. M., Abers, G. A., \& Holloway, S. D. (2003). Subduction factory 2. Are intermediate-depth earthquakes in subducting slabs linked to metamorphic dehydration reactions? Journal of Geophysical Research: Solid Earth, 108(B1).

Harris, R., Yamano, M., Kinoshita, M., Spinelli, G., Hamamoto, H., \& Ashi, J. (2013). A synthesis of heat flow determinations and thermal modeling along the nankai trough, japan. Journal of Geophysical Research: Solid Earth, $118(6), 2687-2702$.

Harris, R. N., Spinelli, G. A., \& Fisher, A. T. (2017). Hydrothermal circulation and the thermal structure of shallow subduction zones. Geosphere, 13(5), $1425-1444$.

Herrendörfer, R., Van Dinther, Y., Gerya, T. V., \& Dalguer, L. A. (2015). Earthquake supercycle in subduction zones controlled by the width of the seismogenic zone. Nature Geoscience, 8(6), 471.

Heuret, A., Lallemand, S., Funiciello, F., Piromallo, C., \& Faccenna, C. Physical characteristics of subduction interface type seismogenic zones revisited. Geochemistry, Geophysics, Geosystems, 12(1).

Hillier, J., \& Watts, A. (2005). Relationship between depth and age in the north pacific ocean. Journal of Geophysical Research: Solid Earth, 110(B2).

Hofmeister, A. (1999). Mantle values of thermal conductivity and the geotherm from phonon lifetimes. Science, 283(5408), 1699-1706.

Hofmeister, A. M. (2007a). Pressure dependence of thermal transport properties. Proceedings of the National Academy of Sciences, 104(22), 9192-9197.

Hofmeister, A. M. (2007b). Thermal conductivity of the earth's deepest mantle. In Superplumes: Beyond plate tectonics (pp. 269-292). Springer.

Holt, A. F., \& Condit, C. B. (2021). Slab temperature evolution over the lifetime of a subduction zone. Geochemistry, Geophysics, Geosystems, e2020GC009476.

Hu, J., \& Gurnis, M. (2020). Subduction duration and slab dip. Geochemistry, Geophysics, Geosystems, 21(4), e2019GC008862.

Hyndman, R. D., \& Peacock, S. M. (2003). Serpentinization of the forearc mantle. Earth and Planetary Science Letters, 212(3-4), 417-432.

Hyndman, R. D., \& Wang, K. (1993). Thermal constraints on the zone of major thrust earthquake failure: The cascadia subduction zone. Journal of Geophysical Research: Solid Earth, 98(B2), 2039-2060.

Hyndman, R. D., Yamano, M., \& Oleskevich, D. A. (1997). The seismogenic zone of subduction thrust faults. Island Arc, 6(3), 244-260.

Isacks, B. L., \& Barazangi, M. (1977). Geometry of benioff zones: Lateral segmentation and downwards bending of the subducted lithosphere. Island Arcs, Deep Sea Trenches and Back-Arc Basins, 1, 99-114.

Jarrard, R. D. (1986). Relations among subduction parameters. Reviews of Geophysics, 24(2), 217-284.

Jia, Z., Shen, Z., Zhan, Z., Li, C., Peng, Z., \& Gurnis, M. (2020). The 2018 fiji mw 8.2 and 7.9 deep earthquakes: One doublet in two slabs. Earth and Planetary Science Letters, 531, 115997.

Jones, D. W. R., Katz, R. F., Tian, M., \& Rudge, J. F. (2018). Thermal impact of magmatism in subduction zones. Earth and Planetary Science Letters, 481, $73-79$.

Jung, H., Green Ii, H. W., \& Dobrzhinetskaya, L. F. (2004). Intermediate-depth earthquake faulting by dehydration embrittlement with negative volume change. Nature, 428(6982), 545-549. 
Karato, S.-i. (2008). Deformation of earth materials. An Introduction to the Rheology of Solid Earth, 463.

Kelemen, P. B., \& Hirth, G. (2007). A periodic shear-heating mechanism for intermediate-depth earthquakes in the mantle. Nature, 446(7137), 787-790.

King, S. D. (2001). Subduction zones: observations and geodynamic models. Physics of the Earth and Planetary Interiors, 127(1-4), 9-24.

Klemd, R., John, T., Scherer, E., Rondenay, S., \& Gao, J. (2011). Changes in dip of subducted slabs at depth: petrological and geochronological evidence from hp-uhp rocks (tianshan, nw-china). Earth and Planetary Science Letters, 310(1-2), 9-20.

Korenaga, T., \& Korenaga, J. (2016). Evolution of young oceanic lithosphere and the meaning of seafloor subsidence rate. Journal of Geophysical Research: Solid Earth, 121(9), 6315-6332.

Liu, H., Gurnis, M., Leng, W., Jia, Z., \& Zhan, Z. (2021). Tonga slab morphology and stress variations controlled by a relic slab: Implications for deep earthquakes in the tonga-fiji region. Geophysical Research Letters, e2020GL091331.

McKenzie, D., Jackson, J., \& Priestley, K. (2005). Thermal structure of oceanic and continental lithosphere. $\quad$ Earth and Planetary Science Letters, 233(3-4), 337349.

McKenzie, D., \& Sclater, J. (1969). Heat flow in the eastern pacific and sea floor spreading. Bulletin Volcanologique, 33(1), 101-117.

Parsons, B., \& Sclater, J. G. (1977). An analysis of the variation of ocean floor bathymetry and heat flow with age. Journal of geophysical research, 82(5), 803-827.

Peacock, S. M. (1992). Blueschist-facies metamorphism, shear heating, and p-t-t paths in subduction shear zones. Journal of Geophysical Research: Solid Earth, 97(B12), 17693-17707.

Peacock, S. M. (1993). Large-scale hydration of the lithosphere above subducting slabs. Chemical Geology, 108(1-4), 49-59.

Peacock, S. M. (2001). Are the lower planes of double seismic zones caused by serpentine dehydration in subducting oceanic mantle? Geology, 29(4), 299-302.

Peacock, S. M. (2009). Thermal and metamorphic environment of subduction zone episodic tremor and slip. Journal of Geophysical Research: Solid Earth, 114 (B8).

Peacock, S. M. (2020). Advances in the thermal and petrologic modeling of subduction zones. Geosphere, 16(4), 936-952.

Peacock, S. M., \& Hyndman, R. D. (1999). Hydrous minerals in the mantle wedge and the maximum depth of subduction thrust earthquakes. Geophysical Research Letters, 26 (16), 2517-2520.

Peacock, S. M., \& Wang, K. (1999). Seismic consequences of warm versus cool subduction metamorphism: Examples from southwest and northeast japan. Science, 286(5441), 937-939.

Penniston-Dorland, S. C., Kohn, M. J., \& Manning, C. E. (2015). The global range of subduction zone thermal structures from exhumed blueschists and eclogites: Rocks are hotter than models. Earth and Planetary Science Letters, 428, 243-254.

Perrin, A., Goes, S., Prytulak, J., Davies, D. R., Wilson, C., \& Kramer, S. (2016). Reconciling mantle wedge thermal structure with arc lava thermobarometric determinations in oceanic subduction zones. Geochemistry, Geophysics, Geosystems, 17(10), 4105-4127.

Petrini, C., Gerya, T., Yarushina, V., van Dinther, Y., Connolly, J., \& Madonna, C. (2020). Seismo-hydro-mechanical modelling of the seismic cycle: methodology and implications for subduction zone seismicity. Tectonophysics, 791, 228504.

Ponko, S. C., \& Peacock, S. M. (1995). Thermal modeling of the southern alaska subduction zone: insight into the petrology of the subducting slab and overly- 
ing mantle wedge. Journal of Geophysical Research: Solid Earth, 100(B11), 22117-22128.

Pozgay, S. H., Wiens, D. A., Conder, J. A., Shiobara, H., \& Sugioka, H. Seismic attenuation tomography of the mariana subduction system: Implications for thermal structure, volatile distribution, and slow spreading dynamics. Geochemistry, Geophysics, Geosystems, 10(4).

Press, W. H., Teukolsky, S. A., Vetterling, W. T., \& Flannery, B. P. (1992). Numerical recipes in $\mathrm{c}++$. The art of scientific computing, 2, 1002.

Ranalli, G. (1995). Rheology of the earth. Springer Science \& Business Media.

Richards, F., Hoggard, M., Cowton, L., \& White, N. (2018). Reassessing the thermal structure of oceanic lithosphere with revised global inventories of basement depths and heat flow measurements. Journal of Geophysical Research: Solid Earth, 123(10), 9136-9161.

Rondenay, S., Abers, G. A., \& Van Keken, P. E. (2008). Seismic imaging of subduction zone metamorphism. Geology, 36(4), 275-278.

Rotman, H. M., \& Spinelli, G. A. (2013). Global analysis of the effect of fluid flow on subduction zone temperatures. Geochemistry, Geophysics, Geosystems, $14(8), 3268-3281$.

Royden, L. H. (1993). The steady state thermal structure of eroding orogenic belts and accretionary prisms. Journal of Geophysical Research: Solid Earth, 98(B3), 4487-4507.

Rüpke, L. H., Morgan, J. P., Hort, M., \& Connolly, J. A. （2004). Serpentine and the subduction zone water cycle. Earth and Planetary Science Letters, 223(12), $17-34$.

Schellart, W. P., \& Rawlinson, N. ～(2013). Global correlations between maximum magnitudes of subduction zone interface thrust earthquakes and physical parameters of subduction zones. Physics of the Earth and Planetary Interiors, 225, 41-67.

Schmeling, H., Babeyko, A., Enns, A., Faccenna, C., Funiciello, F., Gerya, T., ... others (2008). A benchmark comparison of spontaneous subduction models - towards a free surface. Physics of the Earth and Planetary Interiors, $171(1-4), 198-223$.

Scholz, C. H. (2019). The mechanics of earthquakes and faulting. Cambridge university press.

Schubert, G., Turcotte, D. L., \& Olson, P. (2001). Mantle convection in the earth and planets 2 volume set. Cambridge University Press.

Sclater, J., Jaupart, C., \& Galson, D. (1980). The heat flow through oceanic and continental crust and the heat loss of the earth. Reviews of Geophysics, 18(1), 269-311.

Seipold, U. (1998). Temperature dependence of thermal transport properties of crystalline rocks - a general law. Tectonophysics, 291(1-4), 161-171.

Spinelli, G. A., \& Wang, K. (2008). Effects of fluid circulation in subducting crust on nankai margin seismogenic zone temperatures. Geology, 36(11), 887-890.

Stein, C. A., \& Stein, S. (1994). Constraints on hydrothermal heat flux through the oceanic lithosphere from global heat flow. Journal of Geophysical Research: Solid Earth, 99(B2), 3081-3095.

Su, C., Liu, Y., Song, W., Fan, D., Wang, Z., \& Tang, H. (2018). Thermodynamic properties of san carlos olivine at high temperature and high pressure. Acto Geochimica, 37(2), 171-179.

Syracuse, E. M., van Keken, P. E., \& Abers, G. A. (2010). The global range of subduction zone thermal models. Physics of the Earth and Planetary Interiors, 183(1-2), 73-90.

Turcotte, D., \& Schubert, G. (2002). Geodynamics. Cambridge University Press.

van Dinther, Y., Gerya, T. V., Dalguer, L. A., Corbi, F., Funiciello, F., \& Mai, P. M. (2013). The seismic cycle at subduction thrusts: 2. Dynamic implica- 
tions of geodynamic simulations validated with laboratory models. Journal of Geophysical Research: Solid Earth, 118(4), 1502-1525.

van Dinther, Y., Gerya, T. V., Dalguer, L. A., Mai, P. M., Morra, G., \& Giardini, D. (2013). The seismic cycle at subduction thrusts: Insights from seismothermo-mechanical models. Journal of Geophysical Research: Solid Earth, 118(12), 6183-6202.

van Dinther, Y., Mai, P. M., Dalguer, L. A., \& Gerya, T. V. (2014). Modeling the seismic cycle in subduction zones: The role and spatiotemporal occurrence of off-megathrust earthquakes. Geophysical Research Letters, 41(4), 1194-1201.

Van Keken, P., Kita, S., \& Nakajima, J. (2012). Thermal structure and intermediate-depth seismicity in the tohoku-hokkaido subduction zones. Solid Earth, 3(2), 355-364.

van Keken, P. E., Currie, C., King, S. D., Behn, M. D., Cagnioncle, A., He, J., ... others (2008). A community benchmark for subduction zone modeling. Physics of the Earth and Planetary Interiors, 171(1-4), 187-197.

van Keken, P. E., Hacker, B. R., Syracuse, E. M., \& Abers, G. A. (2011). Subduction factory: 4. Depth-dependent flux of $\mathrm{H} 2 \mathrm{O}$ from subducting slabs worldwide. Journal of Geophysical Research: Solid Earth, 116(B1).

van Keken, P. E., Kiefer, B., \& Peacock, S. M. (2002). High-resolution models of subduction zones: Implications for mineral dehydration reactions and the transport of water into the deep mantle. Geochemistry, Geophysics, Geosystems, 3(10), 1-of.

van Keken, P. E., Wada, I., Abers, G. A., Hacker, B. R., \& Wang, K. (2018). Mafic high-pressure rocks are preferentially exhumed from warm subduction settings. Geochemistry, Geophysics, Geosystems, 19(9), 2934-2961.

van Keken, P. E., Wada, I., Sime, N., \& Abers, G. A. (2019). Thermal structure of the forearc in subduction zones: A comparison of methodologies. Geochemistry, Geophysics, Geosystems, 20(7), 3268-3288.

van Zelst, I., Crameri, F., Pusok, A. E., Glerum, A., Dannberg, J., \& Thieulot, C. (2021). 101 Geodynamic modelling: How to design, carry out, and interpret numerical studies. $\quad$ Solid Earth Discussions, 2021, 1-80. Retrieved from https://se.copernicus.org/preprints/se-2021-14/ doi: $10.5194 / \mathrm{se}-2021-14$

Van Zelst, I., Wollherr, S., Gabriel, A.-A., Madden, E. H., \& van Dinther, Y. (2019). Modeling megathrust earthquakes across scales: One-way coupling from geodynamics and seismic cycles to dynamic rupture.

Journal of Geophysical Research: Solid Earth, 124(11), 11414-11446.

Wada, I. (2021). A simple picture of mantle wedge flow patterns and temperature variation. Journal of Geodynamics, 101848.

Wang, J., Zhao, D., \& Yao, Z. (2017). Seismic anisotropy evidence for dehydration embrittlement triggering intermediate-depth earthquakes. Scientific reports, 7(1), 1-9.

Wen, H., Lu, J.-h., Xiao, Y., \& Deng, J. (2015). Temperature dependence of thermal conductivity, diffusion and specific heat capacity for coal and rocks from coalfield. Thermochimica acta, 619, 41-47.

Xu, Y., Shankland, T. J., Linhardt, S., Rubie, D. C., Langenhorst, F., \& Klasinski, K. (2004). Thermal diffusivity and conductivity of olivine, wadsleyite and ringwoodite to 20 gpa and $1373 \mathrm{k}$. Physics of the Earth and Planetary Interiors, 143, 321-336.

Yabe, S., Fukuchi, R., Hamada, Y., \& Kimura, G. (2019). Simultaneous estimation of in situ porosity and thermal structure from core sample measurements and resistivity log data at nankai accretionary prism. Earth, Planets and Space, $71(1), 1-15$.

Yamasaki, T., \& Seno, T. (2003). Double seismic zone and dehydration embrittlement of the subducting slab. Journal of Geophysical Research: Solid Earth, 
108(B4).

1111 Zhan, Z. (2020). Mechanisms and implications of deep earthquakes. Annual Review of Earth and Planetary Sciences, 48, 147-174. 